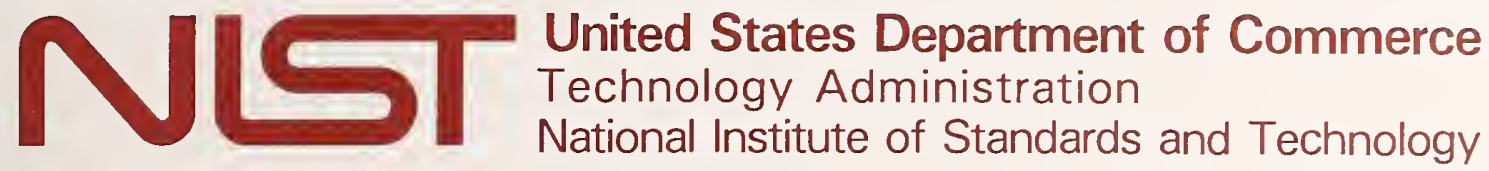

NIST Technical Note 1389

\title{
Measurement Uncertainty of Radiated Emissions
}

David A. Hill Motohisa Kanda

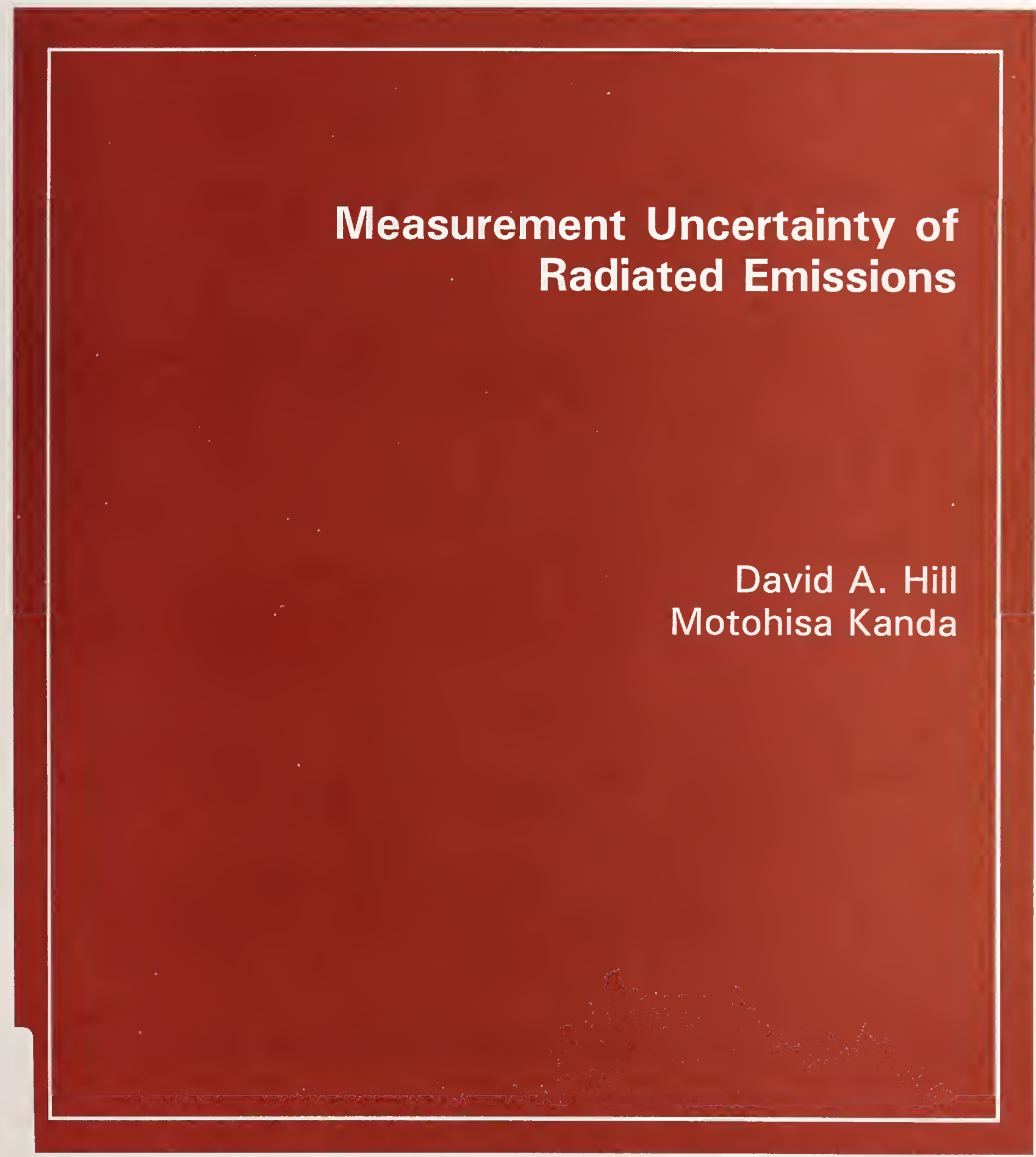

15753 



\section{Measurement Uncertainty of Radiated Emissions}

David A. Hill

Motohisa Kanda

Electromagnetic Fields Division

Electronics and Electrical Engineering Laboratory

National Institute of Standards and Technology

325 Broadway

Boulder, Colorado 80303-3328

March 1997

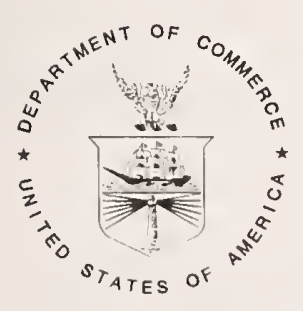

U.S. DEPARTMENT OF COMMERCE, William M. Daley, Secretary TECHNOLOGY ADMINISTRATION, Mary L. Good, Under Secretary for Technology NATIONAL INSTITUTE OF STANDARDS AND TECHNOLOGY, Arati Prabhakar, Director 
National Institute of Standards and Technology Technical Note Natl. Inst. Stand. Technol., Tech. Note 1389, 36 pages (March 1997) CODEN:NTNOEF

\section{U.S. GOVERNMENT PRINTING OFFICE \\ WASHINGTON: 1997}

For sale by the Superintendent of Documents, U.S. Government Printing Office, Washington, DC 20402-9325 


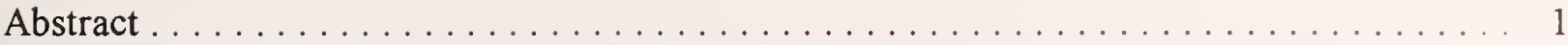

1. INTRODUCTION . . . . . . . . . . . . . . . . . . . . . . . . . . 1

2. SEPARATE AND COMBINED UNCERTAINTIES $\ldots \ldots \ldots \ldots \ldots \ldots \ldots \ldots$

3. SETUP OF EQUIPMENT UNDER TEST $\ldots \ldots \ldots \ldots \ldots \ldots \ldots \ldots \ldots \ldots \ldots \ldots \ldots \ldots$

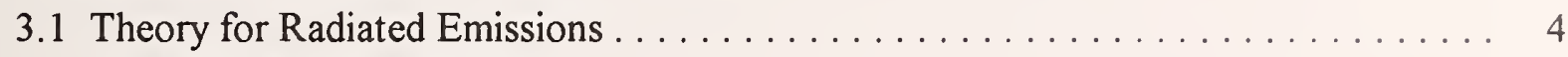

3.2 Measurement Uncertainties ........................... 6

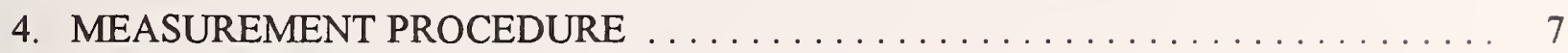

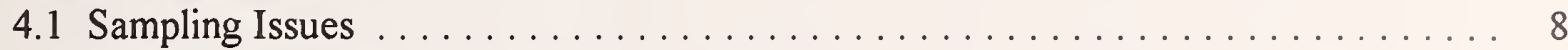

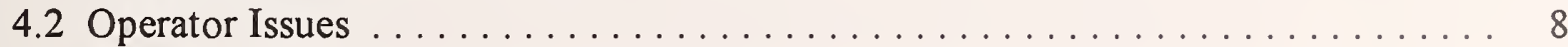

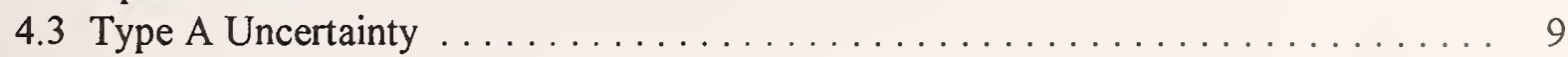

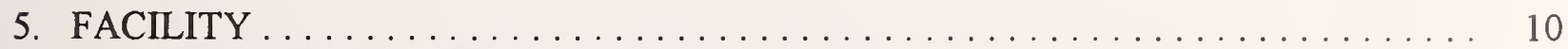

5.1 Open Area Test Site (OATS) . . . . . . . . . . . . . . . . . . . . 10

5.2 Anechoic and Semi-Anechoic Chambers . . . . . . . . . . . . . . . . . 11

5.3 Shielded Enclosure . . . . . . . . . . . . . . . . . . . . . . . . . . . . 11

5.4 Reverberation Chamber . . . . . . . . . . . . . . . . . . . . . . 12

5.5 TEM and GTEM Cells . . . . . . . . . . . . . . . . . . . . . . 12

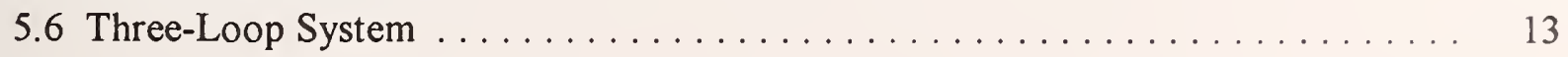

6. ANTENNA ....................................... 13

6.1 Standard-Antenna Method ... . . . . . . . . . . . . . . . . . . . . 13

6.2 Standard-Field Method ................................... 14

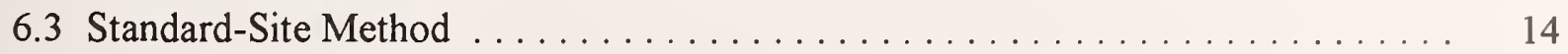

6.4 Reference-Antenna Method ................................. 15

7. RECEIVER ..................................... 15

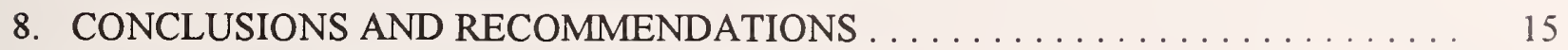

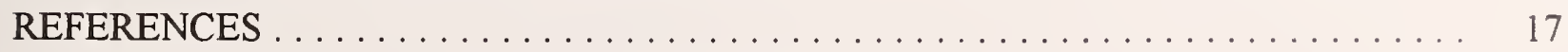

APPENDIX A. PROPAGATION OF UNCERTAINTY . . . . . . . . . . . . 22

APPENDIX B. UNCERTAINTY OF A PRODUCT OF QUANTITIES . . . . . . . . . . 24 



\title{
MEASUREMENT UNCERTAINTY OF RADIATED EMISSIONS
}

\author{
David A. Hill and Motohisa Kanda \\ Electromagnetic Fields Division \\ National Institute of Standards and Technology \\ Boulder, Colorado 80303
}

\begin{abstract}
We present a summary of current knowledge and techniques for evaluating measurement uncertainty of radiated emissions. The important quantity for compliance testing is the expanded uncertainty (typically for a coverage factor $k=2$ ), and we discuss the validity of obtaining the combined uncertainty from an RSS sum of separate uncertainties. A generic uncertainty model includes the following separate sources of measurement uncertainty: setup of equipment under test, measurement procedure, facility, antenna, and receiver. Measurement uncertainties for radiated emissions are large and not well quantified, and recommendations are made for further study.
\end{abstract}

Key words: anechoic chamber; antenna factor; combined uncertainty; compliance testing; expanded uncertainty; measurement uncertainty; open area test site; propagation of uncertainty; radiated emissions; reverberation chamber; shielded enclosure.

\section{INTRODUCTION}

Electromagnetic compatibility (EMC) tests and measurements typically have large uncertainties of at least several decibels [1,2]. Large measurement uncertainty can lead to overdesign and extra expense of a product to achieve EMC or to underdesign and failure to achieve EMC. Consequently, it is important to have a good knowledge of EMC measurement uncertainty and to minimize it to the extent possible.

Most EMC tests and measurements fall into one of the following four categories: (1) radiated emissions, (2) radiated immunity, (3) conducted emissions, or (4) conducted immunity. This report will concentrate on radiated emissions measurements, but many of the individual results will apply equally well to radiated imunity measurements since both types of measurements deal with radiated fields. The purposes of this report are to identify the numerous sources of uncertainty in radiated emissions measurements and to evaluate these uncertainties where possible. In many cases this evaluation is not now possible, and further experimental or theoretical study will be required. Some estimates and examples of radiated emissions measurement uncertainties have been made in references [1] and [2]. 
A diagram for a generic radiated emissions measurement is shown in figure 1. The equipment under test (EUT) could be any electronic device, such as a digital computer, that is capable of emitting electromagnetic radiation. We include cables in figure 1 because they typically affect radiated emissions. In a formal compliance test, the measurement setup and procedure are normally specified in detail, but many other radiated emissions measurements are made without set procedures. This report covers both cases because they involve the same radiated field measurement issues and uncertainties.

The measurement facility could be an outdoor facility, such as an open area test site (OATS) as specified by the Federal Communications Commission (FCC) for measuring radiated emissions from computing devices [3], or an indoor shielded facility, such as an anechoic chamber or a reverberation chamber. The receiving antenna could be any well characterized antenna. A narrowband example is a half-wavelength, tuned dipole, and broadband examples are biconical and log-periodic antennas. A typical receiver is a spectrum analyzer, and in formal compliance tests a minimum receiver bandwidth is normally specified.

The organization of this report is as follows. Section 2 covers methods for reporting separate measurement uncertainties and combined or total uncertainty. Sections 3 through 7 cover the separate uncertainties associated with EUT setup, measurement procedure, facility, antenna, and receiver respectively. Section 8 includes conclusions and recommendations for further study. Appendix A examines propagation of uncertainty as derived from a Taylor series expansion. Appendix B examines propagation of uncertainty for the special case where an estimated value is based on a product of measured values.

\section{SEPARATE AND COMBINED UNCERTAINTIES}

In a radiated emissions test, the measured quantity can be electric field strength $(\mathrm{V} / \mathrm{m})$, magnetic field strength $(\mathrm{A} / \mathrm{m})$, or radiated power $(\mathrm{W})$. All three are positive, real quantities. However, they are frequently expressed in decibels $(\mathrm{dB})$ relative to some convenient level. For example, radiated electric field measurements or emissions limits [4] are frequently referred to $1 \mu \mathrm{V} / \mathrm{m}$ and are expressed in $\mathrm{dB}(1 \mu \mathrm{V} / \mathrm{m})$. When field strength or power is expressed in decibels relative to some reference level, it can be positive or negative.

If the standard uncertainty of a measured emission is evaluated statistically, then it is classified as Type A [5,6]. Type B uncertainties are those which are evaluated by other means. It is strongly recommended that corrections be applied for known systematic effects, but in practice such corrections may not be made because of limited resources or because of the insignificance of a particular systematic effect. Even when a correction is made, a type B uncertainty remains due to an incomplete knowledge of the value of the correction. In keeping with the notation in reference [5], we use the symbol $u_{i}$ to represent standard uncertainty due to the $i$ th effect. It is equal to the positive square root of the estimated variance $u_{i}^{2}$.

The usual method for combining separate standard uncertainties to determine the combined standard uncertainty $u_{c}[5]$ is the root sum of squares (RSS):

$$
u_{c}^{2}=\sum_{i} u_{i}^{2}
$$


The justification of the RSS combination in eq (1) is discussed in Appendix A. For radiated emissions measurements where the relative $u_{i}$ values are not necessarily small, the RSS combination may not be valid. This issue requires further study.

In addition to the combined standard uncertainty $u_{c}$ of a measured emission, an expanded uncertainty, $U=k u_{c}$, is also a useful quantity. The coverage factor $k$ can be chosen to achieve a desired confidence level [5]. NIST generally uses a value of $k=2$, and this value was also chosen in a recent uncertainty analysis of radar cross-section measurements [7]. For a normal distribution, the choice of $k=2$ yields a 95 percent certainty that the error is bounded by $\pm U$. A probable error (equal to $0.675 u_{c}$ ) has been defined as the error that is exceeded 50 percent of the time [1, Sec. 8.1.2].

In some cases probability distributions other than normal, such as rectangular, $\mathrm{U}$ shaped, or log normal, have been found useful in EMC measurement uncertainty studies [1,2]. The rectangular distribution has been suggested for cases when the "worst case" limits are known (perhaps from manufacturer specifications) but no additional information is available. This distribution assigns an equal probability lying anywhere between the prescribed limits. If the worst-case limits are $\pm a_{i}$, then the standard uncertainty $u_{i}$ can be derived: $u_{i}=a_{i} / \sqrt{3}$. Although this is an appropriate value for the standard uncertainty, some modification is required in using it for calculating the expanded uncertainty. For a coverage factor $k=2$, the expanded uncertainty $U_{i}$ is $U_{i}=2 u_{i}=2 a_{i} / \sqrt{3}$. Since this value for 95 percent confidence exceeds the prescribed limit $a_{i}$, it is obviously an overestimate. Possible modifications are (1) to revisit the initial rectangular distribution assumption, (2) to set $U_{i}=a_{i}$, or (3) to set $u_{i}=a_{i} / 2$ before calculating $u_{c}$ and $U$.

In the EMC community, relative errors or uncertainties have commonly been expressed in decibels $[8,9]$. If the combined standard uncertainty is small, then the logarithmic standard uncertainty is linearly related to the relative value. For example, if we are measuring an electric or magnetic field strength, the approximate relationship is

$$
u_{c}(d B)=8.686 u_{c} .
$$

If we are dealing with radiated power rather than field strength, then the coefficient 8.686 in eq (2) is changed to 4.343 . Generally radiated-emissions measurements do not have small combined standard uncertainties, and eq (2) is not valid. A convenient assumption that is commonly made in EMC measurements is that the probability density function is log normal [1]. Then decibel values have a normal distribution, and there is no need to convert to relative values in performing the RSS in eq (1). Some theoretical and experimental justification for the log normal distribution is given in [10]. The theoretical explanation is that the measured quantity can be represented by a product of a large number of random factors so that the log of the measured quantity becomes a sum to which the central-limit theorem [11] applies. For convenience we will also quote uncertainties in decibels in most of this report, but uncertainties should generally be converted to relative values before evaluating eq (1). However, for cases involving large uncertainties, the convenient assumption of a log normal distribution allows the use of decibel values and yields symmetric positive and negative uncertainties in decibels. It also avoids the nonphysical result of negative radiated power in the negative uncertainty interval. The issue of how to handle large 
negative uncertainties needs further study to put it on a rigorous basis.

The issue of how to use uncertainty estimates in compliance testing is currently unresolved [12]. One approach [2] is that the measured emission level plus the expanded uncertainty $U$ (usually for $k=2$ ) must be less than the specified emission limit for one to state that the EUT complies. By the same approach, the EUT does not comply if the measured emission level minus the expanded uncertainty exceeds the specified limit. If the measured emission level is within $\pm U$ of the specified limit, then it is unknown whether the EUT complies. The other approach is based on the assumption that the specification limit already includes a margin for the expanded uncertainty. Then compliance is determined only by the measured emission level, and the measurement laboratory does not have to take its measurement uncertainty estimate into account in determining whether the EUT complies. Regardless of which approach is ultimately agreed upon, it is desirable to quantify and to reduce measurement uncertainty.

\section{SETUP OF EQUIPMENT UNDER TEST}

\subsection{Theory for Radiated Emissions}

Before considering measurement issues, we review some basic radiation theory. The actual sources and currents within a real EUT are typically very complicated, but we can simplify the radiation theory by surrounding the EUT by a surface $S$ as shown in figure 2 . Then the radiated electric field $\vec{E}(\vec{r})$ outside $S$ can be written as a surface integral of the tangential components of the surface electric field $\vec{E}(\vec{r})$ and magnetic field $\vec{H}(\vec{r})$ :

$$
\vec{E}(\vec{r})=\nabla \times \iint_{S} \hat{n}^{\prime} \times \vec{E}(\vec{r}) g d S^{\prime}+\frac{1}{j \omega \epsilon_{0}} \nabla \times \nabla \times \iint_{S} \hat{n}^{\prime} \times \vec{H}(\vec{r}) g d S^{\prime},
$$

where $g=\exp \left(-j k_{0} R\right) /(4 \pi R), R=\left|\overrightarrow{\boldsymbol{r}}-\overrightarrow{\boldsymbol{r}}^{\prime}\right|, k_{0}=\omega \sqrt{\mu_{0} \epsilon_{0}}$, the vector $\overrightarrow{\boldsymbol{r}}^{\prime}$ designates the source point on $S$, and $\hat{n}^{\prime}$ is the outward unit normal to $S$. The time dependence is $\exp (j \omega t)$, so eq (3) represents one spectral component of a general time-varying field. Tai has called eq (3) the Franz formula [13], and there is a dual equation for the radiated magnetic field. We have assumed that the region outside $S$ is free space with permittivity $\epsilon_{0}$ and permeability $\mu_{0}$, but the effect of a perfectly conducting ground plane (assumed for an OATS facility) could be included by image theory.

Equation (3) could apply to any radiator enclosed within the surface $S$. The equivalence principle [14] states that the fields in the integrands could be replaced by surface electric currents $\vec{K}_{e}(\vec{r})$ and magnetic currents $\vec{K}_{m}(\vec{r})$ radiating in free space:

$$
\vec{K}_{e}(\vec{r})=\hat{n}^{\prime} \times \vec{H}(\vec{r}) \text { and } \vec{K}_{m}(\vec{r})=-\hat{n}^{\prime} \times \vec{E}(\vec{r})
$$

Since the currents in eq (4) are only equivalent currents, they radiate the same field as the EUT outside $S$, but do not provide much insight to the radiation process. 
Better insight can be obtained by shrinking the surface down to the boundaries of the EUT. Figure 3 shows a simple example where the EUT comprises two metal boxes with apertures and a connecting cable. By breaking the surface into three parts, we can write the radiated field in eq (3) as a sum of three terms:

$$
\vec{E}(\vec{r})=\vec{E}_{m}(\vec{r})+\vec{E}_{e}(\vec{r})+\vec{E}_{c}(\vec{r}),
$$

where $\vec{E}_{m}$ is the electric field radiated by the metal surface $S_{m}, \vec{E}_{a}$ is the electric field radiated by the apertures $S_{\mathrm{a}}$, and $\overrightarrow{\boldsymbol{E}}_{c}$ is the electric field radiated by the cable surface $S_{\mathrm{c}}$.

If we assume that the metal surface $S_{\mathrm{c}}$ is perfectly conducting, then the tangential electric field is zero, and the tangential magnetic current determines the actual surface current:

$$
\hat{n}^{\prime} \times \vec{E}(\vec{r})=0 \text { and } \hat{n}^{\prime} \times \vec{H}(\vec{r})=\vec{K}(\vec{r}) \text { on } S_{m} .
$$

From eqs (3) and (6), we can write $\vec{E}_{m}$ as

$$
\vec{E}_{m}(\vec{r})=\frac{1}{j \omega \epsilon_{0}} \nabla \times \nabla \times \iint_{S_{m}} \overrightarrow{\boldsymbol{K}}_{e}(\vec{r}) g d S^{\prime}
$$

If $\mathrm{S}_{\mathrm{m}}$ is a real metal with a nonzero skin depth, then $\vec{K}$ is the current flowing within a thin layer at the surface.

The field radiated by the total aperture surface cannot be simplified because both the tangential electric and magnetic fields are nonzero. Thus the expression for $\vec{E} a$ is similar to $\vec{E}$ in eq (3):

$$
\vec{E}_{a}(\vec{r})=\nabla \times \iint_{S_{a}} \hat{n}^{\prime} \times \vec{E}(\vec{r}) g d S^{\prime}+\nabla \times \nabla \times \iint_{S_{a}} \hat{n}^{\prime} \times \vec{H}(\vec{r}) g d S^{\prime} .
$$

The aperture surface $S_{\mathrm{a}}$ is not necessarily free space. It could be any penetrable material such that both the tangential electric and magnetic fields are nonzero.

If the cable is thin, then the field radiated from $S_{\mathrm{c}}$ depends only on the bulk cable current $I_{b}\left(L^{\prime}\right)$, where $L^{\prime}$ is the linear position along the cable. The resultant expression for $\vec{E}_{c}$ is

$$
\vec{E}_{c}(\vec{r})=\frac{1}{j \omega \epsilon_{0}} \nabla \times \nabla \times \int_{L_{c}} \hat{e}_{c}^{\prime} I_{b}(L) g d L,
$$

where the integration is along the cable length $L_{\mathrm{c}}$ and $\hat{\boldsymbol{e}}_{c}^{\prime}$ is a unit vector directed along the cable. Even if the EUT is very complex with many apertures and cables, the total radiated field 
can still be broken down as in eq (5). The integrals in eqs (7) through (9) need to extend over the total conductor surface, aperture surface, or cable length.

The far-field approximations to eqs (7) through (9) are obtained by setting $k_{0} r>>1$, where $r=|r|$, and retaining only $r^{-1}$ terms:

$$
\begin{gathered}
\vec{E}_{m}(\vec{r}) \approx \frac{j k_{0} \eta_{0} e^{-j k_{0} r}}{4 \pi r} \hat{\boldsymbol{r}} \times \hat{\boldsymbol{r}} \times \iint_{S_{m}} \overrightarrow{\boldsymbol{K}}_{e}(\vec{r}) e^{j k_{0} \hat{r}^{\circ} \vec{r}^{\prime}} d S^{\prime}, \\
\vec{E}_{a}(\vec{r}) \approx \frac{-j k_{0} e^{-j k_{0} r}}{4 \pi r} \hat{\boldsymbol{r}} \times \iint_{S_{a}}\left\{\hat{n}^{\prime} \times \vec{E}(\vec{r})-\eta_{0} \hat{r} \times[\hat{n} \times \vec{H}(\vec{r})]\right\} e^{j k_{0} \hat{r}^{\circ} \vec{r}^{\prime}} d S^{\prime},
\end{gathered}
$$

and

$$
\vec{E}_{c}(\vec{r}) \approx \frac{j k_{0} \eta_{0} e^{-j k_{0} r}}{4 \pi r} \hat{\boldsymbol{r}} \times \hat{\boldsymbol{r}} \times \int_{L_{c}} \hat{e}_{c}^{\prime} I_{b}(L) e^{j k_{0} \hat{r} \cdot \vec{r}^{\prime}} d L^{\prime},
$$

where $\eta_{0}=\left(\mu_{0} / \epsilon_{0}\right)^{1 / 2}$ and $\hat{\boldsymbol{r}}=\overrightarrow{\boldsymbol{r}} / r$. When $k r$ is not large, the general eqs (7) through (9) need to be used. Then the curl and curl-curl operations generate $r^{-2}$ (induction field) and $r^{-3}$ (quasi-static field) terms in addition to $r^{-1}$ terms.

\subsection{Measurement Uncertainties}

The general categories of uncertainty sources related to the EUT setup can be lumped into:

(1) EUT mode of operation,

(2) EUT physical configuration, and

(3) cable configuration.

Cable configuration could be lumped under EUT physical configuration, but we choose to treat it as a separate category because it is important and sometimes dominates the radiation.

If an EUT has $\mathrm{M}$ modes of operation, then a complete test would include $\mathrm{M}$ emission tests, one for each mode of operation. (Since an emission measurement for each of the $\mathrm{M}$ modes of operation includes sampling in frequency, angle, and polarization, the number of required individual measurements could be very large.) This is generally too time consuming to be practical, and for some EUTs, such as computers, $\mathrm{M}$ is not even well defined. An emission test 
typically requires that the test be performed for the mode of maximum radiation. Unfortunately, the mode of maximum radiation might well be a function of frequency. Typically the manufacturer will have some knowledge of the likely radiation mechanism and the mode of maximum radiation. However, this issue requires further study, and we know of no estimates of uncertainty due to multiple modes of operation.

The physical EUT configuration affects the geometry of the surfaces, $S_{m}$ and $S_{a}$, and the cable layout $L_{w}$ as shown in figure 3. Even if the surface and cable currents and the aperture fields remain unchanged when components are moved, the radiated electric field as given by eqs (7) through (9) will be affected by changes in $\vec{r}^{\prime}$ (and hence $R$ ). Estimates of the effects of configuration changes could be made from eqs (7) through (9), but in general the currents and aperture fields in the integrands are not known and would change with changes in the EUT configuration. Modern computational techniques $[15,16]$ and experimental studies would be useful for estimating radiation changes (and uncertainties) due to EUT configuration. Some analytical error estimates based on simple path length effects have been presented [1, Sec. 8.4.1], but these estimates neglect phase effects.

Cable configuration effects could be lumped with general EUT configuration effects, but they are so prevalent $[17,18]$ that we chose to separate them. In some radiated emissions tests, the lengths, terminations, and positions of power cables and interconnecting leads are prescribed in detail [1, Sec. 9.2.2], but often they are to be configured to maximize emissions. Radiated emissions from simple cable geometries can be described analytically [3, Sec. 8.1]. These simple geometries are useful for determining the dependence of cable radiation on parameters such as cable length, loop area, current magnitude, and frequency, and they could be used to generate useful numerical results for variations in emissions as a function of cable layout. Experimental studies would be useful for more complex EUTs with multiple boxes and cables. Such studies have not yet been performed with the goal of estimating measurement uncertainty of radiated emissions. An expanded uncertainty of $2 \mathrm{~dB}$ has been suggested for cable layout effects [8], but this general area, especially termination effects, needs further study.

Since we have no precise uncertainty estimates on any of the EUT categories (mode of operation, physical configuration, or cable layout), this is clearly a weak area in overall measurement uncertainty knowledge that merits extensive study. This is particularly true because the uncertainties due to EUT setup are expected to be large [8]. In the following sections, we will see that some estimates of uncertainties due measurement techniques and facilities already exist, but there are also large gaps.

\section{MEASUREMENT PROCEDURE}

Measurement procedures and facilities for radiated emissions measurements are summarized in reference $[1, \mathrm{Ch} .8]$. The details of the procedure differ for various facilities, but sampling, operator, and repeat issues are common to all the methods. 


\subsection{Sampling Issues}

The total number $N_{t}$ of measurements required in a test can be written

$$
N_{t}=M \cdot S \cdot A \cdot H \cdot P \cdot F,
$$

where $M$ is the number of modes of operation, $S$ is the number of setup configurations (box locations and cable layouts), $A$ is the number of azimuthal angle locations for the receiving antenna, $H$ is the number of heights for the receiving antenna, $P$ is the number of polarizations (usually two) of the receiving antenna, and $F$ is the number of frequency samples. For even modest values of $M, S, A, H, P$, and $F$, the total number $N_{t}$ of measurements required to minimize sampling errors can be very large (on the order of $10^{6}$ ).

Since $N_{t}$ is constrained by time and other practical considerations, there will be errors caused by undersampling. Some considerations in choosing $M, S, A, H$, and $F$ efficiently have been discussed in [1, Sec. 9.4], but the measurement uncertainties resulting from undersampling have apparently not been studied. Some analytical studies of field sampling effects based on the electrical size of the EUT could be performed using modern antenna measurement theory [19], and this covers $A$ and $H$ effects. However, the uncertainties caused by undersampling in $M, S$, and $F$ need to be studied experimentally.

\subsection{Operator Issues}

Operator errors can occur in setting up the EUT and the receiving equipment and in taking instrument readings (particularly for analog readouts). Automation of measurements has eliminated some operator errors (such as instrument misreadings), but it introduces possible uncertainty due to software errors. The uncertainties due to the operator instrument readings or software have not been evaluated and are usually assumed to be negligible under normal conditions.

However, we can evaluate the uncertainty in the measured electric (or magnetic) field strength due to uncertainty in distance (caused by operator setup). For cases where the receiving antenna is in the far field, the field falls off as the reciprocal of distance $r$. From the theory for the propagation of uncertainty as covered in Appendix A, the standard uncertainty $u_{r}$ in the measured electric field strength $E$ due the standard uncertainty $u(r)$ is

$$
u_{r}=\left|\frac{\partial E}{\partial r}\right| u(r)=\frac{E}{r} u(r) .
$$

Since the relative uncertainty $u_{r} / E$ equals $u(r) / r$, the standard uncertainty in decibels is

$$
u_{r}(\mathrm{~dB})=-20 \log _{10}\left[1-\frac{u(r)}{r}\right] \approx 8.686 \frac{u(r)}{r} .
$$


The final expression in eq (15) assumes that $u(r) / r$ is small. For example, the table of typical uncertainties in reference [2] gives a rectangular distribution with $u_{r}=0.4 / \sqrt{3} \mathrm{~dB} \approx 0.23 \mathrm{~dB}$ for a distance of $10 \mathrm{~m}$. From eq $(15)$, this corresponds to $u(r) / r \approx 0.027$ or $2.7 \%$. This relative uncertainty seems large for a distance measurement, but might be based on the difficulty of defining the distance from a complicated EUT. For cases where the receiving antenna is not in the far field of the EUT, the distance dependence is more complex and probably unknown, and eqs (14) and (15) are not valid. However, some approximations for $r^{-3}$ quasi-static, near-field variation can be obtained [1].

\subsection{Type A Uncertainty}

If $n$ repeat runs of an emission measurement $y_{k}$ are made, then the standard uncertainty $u_{A}(y)$ equals the estimated standard deviation of the mean $\bar{y}$ which by type A evaluation is [5]

$$
u_{A}(y)=\left(\frac{1}{n(n-1)} \sum_{k=1}^{n}\left(y_{k}-\bar{y}\right)^{2}\right)^{1 / 2} \text {, where } \bar{y}=\frac{1}{n} \sum_{k=1}^{n} y_{k} \text {. }
$$

Equation (16) can be considered an evaluation of system repeatability based on $n$ repeat measurements. For example, reference [2] suggests a typical Type A standard uncertainty value of $0.5 \mathrm{~dB}$ for five repeat runs. In the example table in reference [2], this Type A uncertainty is added to the Type B uncertainties by RSS.

In a typical radiated emissions measurement, time and efficiency dictate that no additional repeat measurements are made $(n=1)$. In such cases, it is reasonable to base the Type A uncertainty on previous system repeat measurements by setting the standard uncertainty equal to the standard deviation $s(y)$ :

$$
u_{A}(y)=s(y)=\left(\frac{1}{n-1} \sum_{k=1}^{n}\left(y_{k}-\bar{y}\right)^{2}\right)^{1 / 2} .
$$

By comparing eqs (16) and (17), we see that the standard deviation in eq (17) is reduced by a factor of $n^{-1 / 2}$ when $n$ repeat runs are performed on the actual emissions measurement and the standard uncertainty is given by eq (16). If no previous system repeat runs are performed, then the Type A uncertainty needs to be accounted for in the separate uncertainties as discussed in Appendix A. When a radiated emission $y$ is a function of a number of quantities $x_{i}$, the uncertainty of $y$ can be determined from the uncertainties of $x_{i}$ by the propagation-of-uncertainty equation as in Appendix A. If a Type A evaluation of the uncertainty of the input estimate $u\left(x_{i}\right)$ is performed, the appropriate expression is the same as eq (16):

$$
u\left(x_{i}\right)=\left(\frac{1}{n(n-1)} \sum_{k=1}^{n}\left(x_{i, k}-\bar{x}_{i}\right)^{2}\right)^{1 / 2} \text {, where } \bar{x}_{i}=\frac{1}{n} \sum_{k=1}^{n} x_{i, k}
$$


and $x_{i, k}$ is the $k$ th sample of $x_{i}$

In selecting the coverage factor $k$ for the expanded uncertainty $U$ of quantities, the uncertainty in the estimated uncertainty must be accounted for in order to achieve the desired confidence level (95\%). A table of $k$ values is given in [5]. For large $n, k$ approaches 2, but smaller values of $n$ require a somewhat larger value of $k$.

\section{FACILITY}

A variety of facilities can be used for radiated emissions measurements, and they attempt to simulate different radiation conditions, such as free space, half space, or guided wave. Consequently, we will discuss the various facilities and their contribution to measurement uncertainty separately.

\subsection{Open Area Test Site (OATS)}

An OATS attempts to simulate a half-space environment bounded by a perfectly conducting plane. The ideal geometry is shown in figure 4 where the EUT and the receiving antenna are located over an infinite ground plane and separated by a horizontal distance D (for example 3 or $10 \mathrm{~m}$ ). For this ideal geometry, the OATS makes no contribution to measurement uncertainty, but a real-world OATS will have construction imperfection limitations and ambient fields that contribute to measurement uncertainty. Practical construction limitations of OATS are: (1) finite extent of the ground plane, (2) irregularities in the ground plane surface, (3) imperfect conductivity of the ground plane, and (4) reflecting objects in the vicinity.

Item 1 is unavoidable, but a typical requirement is that the ground plane be flat and obstruction-free over an elliptical area with a major axis at least twice the horizontal measurement distance and a minor axis at least $\sqrt{3}$ times the horizontal measurement distance [1, Sec. 7.1.1.1]. An estimate of the magnitude of fields diffracted from the edges of the ground plane could be obtained from the geometrical theory of diffraction [20]. An experimental evaluation of edge reflections could be obtained on a large ground plane by performing site attenuation measurements [21] at various distances from ground plane edges.

Ground plane surface irregularities can occur where ground plane sections join or where wire-mesh screens buckle from weathering or extended use. The Rayleigh roughness criterion [22] is a simple requirement for the maximum surface deviation $h$ for which a rough surface will act like a smooth surface. It is based on a maximum phase variation of $\pi / 2$ for reflected rays and for arbitrary incidence angle is given by $h<\lambda_{0} / 8$, where $\lambda_{0}$ is the free-space wavelength. For a maximum frequency of $1 \mathrm{GHz}$, this criterion gives $h<3.75 \mathrm{~cm}$, but this will need to be reduced as the maximum frequency is raised to $2 \mathrm{GHz}$ or higher. This is a fairly crude criterion, and perturbation theory for rough surface scattering [23] could be used to provide estimates of measurement uncertainty caused by ground plane roughness.

All ground planes are imperfect conductors, but solid metal sheets have conductivities on the order of $10^{7} \mathrm{~S} / \mathrm{m}$ and can be considered perfect conductors for practical purposes. Wire mesh screens [24] can be used for ground planes if the mesh periodicity is sufficiently small (typically 
less than $\lambda_{0} / 10$ ). Reflection coefficients for nonmetal materials depend on incidence angle and polarization [25] and can depart significantly from the ideal value of one.

Reflecting objects should be well clear of the elliptical area described above, but even more distant reflectors can introduce significant reflections if they large enough (vehicles, buildings, etc.). If sites are covered, the cover can introduce significant reflections, particularly if it is wet or dirty.

Because of the all the factors that contribute to OATS uncertainty, measurement uncertainty studies have not attempted to analyze the individual effects separately. Instead the approach has been to perform site attenuation measurements [21] or radiated emission measurements $[26,27]$ with the same source at multiple sites. These results are very useful for evaluating uncertainty for measurements made on OATS, but they do not allow isolation of the component of uncertainty due to OATS from other uncertainty sources (antennas, mismatch, receiver, etc.). Reference [2] shows a worst-case uncertainty (rectangular distribution) of $2 \mathrm{~dB}$ for OATS imperfections, and that is consistent with the uncertainties determined in references $[21,26,27]$. As expected, it is less than the maximum $4 \mathrm{~dB}$ deviation from the theoretical ideal site attenuation required for qualification of an OATS for radiation emission measurement from computing devices [3].

The uncertainty due to ambient fields is variable and hard to assess. There are certain times and frequencies when the ambient field levels at the National Institute of Standards and Technology OATS are too high to perform antenna calibrations. Kolb [27] reports the same problem with radiated emission measurements at a number of sites. Reference [2] lists ambient signals as a possible source of measurement uncertainty, but does not give any typical values.

\subsection{Anechoic and Semi-Anechoic Chambers}

Anechoic (absorber-lined) chambers attempt to simulate a free-space environment with no reflections. Semi-anechoic chambers have a conducting floor and attempt to simulate an OATS with only a ground reflection. Semi-anechoic chambers can be used as an alternative to OATS if they can demonstrate equivalence by showing agreement of site attenuation measurements with theory [28]. Both anechoic and semi-anechoic chambers have an advantage over OATS because they are shielded from external ambient fields.

The primary source of measurement uncertainty due to the anechoic chambers is wall reflections (single or multiple). Absorber design and the ability to analyze [29] and to measure $[30,31]$ absorber reflectivity are improving, but it is still difficult to evaluate measurement uncertainty in anechoic chambers. A recent paper [32] showed agreement between measured and theoretical site attenuation within $4 \mathrm{~dB}$ at frequencies from 35 to $1000 \mathrm{MHz}$, but poorer agreement at $30 \mathrm{MHz}$. Because of the push for indoor measurements and improvements in absorber, anechoic and semi-anechoic chamber measurement uncertainty should eventually approach OATS measurement uncertainty.

\subsection{Shielded Enclosure}

Shielded enclosures are typically well-shielded rectangular cavities with metal walls [ 1 , 
Sec. 7.2]. They have the advantage of shielding from external ambient fields and are specified for MIL-STD-462 radiated emissions measurements. However, they are known to produce large uncertainties [33] in radiated emissions measurements.

Strong wall reflections and cavity resonances [1, Sec. 8.2.2.2] affect both the EUT radiation and the receiving antenna factor [34]. Radiated emissions measurements with a wellcharacterized spherical dipole radiator have been performed at a number of different shielded enclosures [35], and large variations have been reported from site to site and day to day. The overall results in reference [35] imply an expanded uncertainty of approximately $10 \mathrm{~dB}$ with values increasing to $20 \mathrm{~dB}$ at cavity resonances.

These uncertainty values are so large that the RSS uncertainty combination with other uncertainties based on a first-order Taylor series is clearly not valid. However, in such a case the clear course of improvement would be to concentrate on reducing the large uncertainty due to shielded enclosure effects. A step in this direction is to introduce some absorber in shielded enclosure measurements [36] with the intent of decreasing cavity $Q$. It remains to be determined how effective this will be and how well this will work at low frequencies where absorber is less effective. The limit of this approach would be to go to an anechoic chamber.

\subsection{Reverberation Chamber}

The reverberation chamber (also called mode-stirred chamber) is a high- $\mathrm{Q}$, multimode cavity which uses either mechanical $[37]$ or frequency $[38,39]$ stirring to obtain field uniformity. Up to now only mechanical stirring has been used for emissions measurements. The quantity measured is the total radiated power $[40,41]$ rather than the maximum electric field strength at a specified distance.

The measurement method is to compare the power received with a reference receiving antenna when the EUT is radiating with that when a known power is fed to a well-characterized transmitting antenna as in figure 5 . The main source of measurement uncertainty is imperfect spatial uniformity in the chamber fields. The expanded uncertainty due to this effect is approximately $3 \mathrm{~dB}[37,41]$, but this value can be reduced with improved stirring and data processing [42]. Antenna patterns have little effect in reverberation chamber measurements, but input impedance and efficiency affect the reference measurement and can introduce an additional expanded uncertainty on the order of $1 \mathrm{~dB}[41,42]$.

\subsection{TEM and GTEM Cells}

The transverse electromagnetic (TEM) cell is a single-mode, guided-wave structure as shown in figure 6. The center region is a rectangular coaxial transmission line, and transition sections taper down to the two ports. If the EUT is electrically small, the free-space radiation pattern and the total radiated power can be determined from two-port measurements with the EUT in several orientations [43]. Because the TEM cell needs to be operated in the single-mode region below the cutoff frequencies of the higher-order modes [44], this is a low-frequency method.

An uncertainty analysis of standard field generation with TEM cells [45] has shown an 
expanded uncertainty of $0.8 \mathrm{~dB}$. Measurement of an electric dipole moment [43] with the geometry in figure 6 has shown a low expanded uncertainty of $0.2 \mathrm{~dB}$, but a more complex EUT which will have more electric dipole and magnetic dipole components can be expected to have a larger measurement uncertainty. Consequently, the $0.8 \mathrm{~dB}$ measurement uncertainty for TEM cell measurements found in [45] is probably a realistic value for expanded uncertainty.

The gigahertz transverse electromagnetic (GTEM) cell [46] is a tapered version of figure 6 with a broadband termination in place of Port 2. It has the advantage of a broad bandwidth, but has larger measurement uncertainty because it is a nonuniform structure with a complex termination. It has been used to perform radiated emissions measurements from 30 to $1000 \mathrm{MHz}$, but further work is needed on evaluating its measurement uncertainty for general EUTs.

\subsection{Three-Loop System}

The three-loop system [47] comprises three orthogonal loop antennas, each with two oppositely located loads as shown in figure 7. If an electrically small EUT is located at the center, the radiation characteristics can be determined in terms of three equivalent electric dipoles and three equivalent magnetic dipoles in a manner analogous to TEM cell measurements [43]. Both methods are restricted to low frequencies, but the three-loop system has the advantage that the EUT does not have to be rotated.

Some experimental uncertainty analysis has been performed for the three-loop system [48] by using a controlled spherical dipole radiator as the source. The expanded uncertainty is approximately $2.5 \mathrm{~dB}$, but further uncertainty study is required.

\section{ANTENNA}

This section discusses methods for determining antenna factors of antennas used for radiated emission measurements for the frequency range between 30 and $1000 \mathrm{MHz}$. Antennas applicable for this measurement are linearly polarized antennas such as tuned dipoles, biconical dipoles, and log periodic arrays. The typical calibration methods used for this task include standard antenna, standard field, standard site, and reference antenna $[49,50]$.

\subsection{Standard-Antenna Method}

The standard-antenna method used at NIST involves half-wave dipole receiving antennas at the open area test site (OATS) typically for the frequency range between 30 and $1000 \mathrm{MHz}$ $[51,52]$. The NIST standard antennas are self-resonant, half-wave dipoles with a high-impedance, balanced voltmeter built across the center gap of the dipole. The calibrating field strength is determined from the effective length and the open-circuit rf voltage induced in the standard dipole. The effective length of the standard dipole having a length near self resonance is presently calculated through a simple Schelkunoff formula [53] and is accurate within $0.1 \mathrm{~dB}$ (expanded uncertainty). We are now in the process of recalculating this effective length by use of the method of moments, and this will be reported later along with the uncertainty of the numerical 
theoretical model.

Other sources of uncertainty in the standard-antenna method involve uncertainties in the $\mathrm{dc}$ to $\mathrm{rf}$ voltage transfer and the various instruments used such as spectrum analyzers, if voltmeters and power monitors, uncertainties in the disturbance of the field caused by the ground screen edges, interconnecting cables and nearby buildings, and uncertainties associated with antenna alignments, antenna heights and separation distances. Uncertainty analyses of these effects are currently underway at NIST.

\subsection{Standard-Field Method}

The standard-field method used to establish reference cw field strengths in the NIST anechoic chamber uses a series of standard-gain, open-ended waveguides from 200 to $500 \mathrm{MHz}$ and pyramidal horns from 500 to $1000 \mathrm{MHz}$ [54-56]. The gain of an open-ended waveguide has been studied experimentally and theoretically [54,55]. The expanded uncertainty of this gain is about $0.1 \mathrm{~dB}[54,55]$, but further analysis by the method of moments is underway at NIST. Standard fields above $500 \mathrm{MHz}$ are produced by a series of standard-gain, pyramidal horns. Currently we use a simple formula derived by aperture integration for the far-field and near-field gains [56]. The expanded uncertainty of the near-field gain is estimated to be $0.5 \mathrm{~dB}$ [57], but this area requires further study. Other uncertainty sources involve uncertainty in the magnitude of multipath reflections within the anechoic chamber, the various instruments such as directional couplers, incident and reflected power monitors, and uncertainty associated with antenna alignments and antenna separation distances.

For the calibration of vertically polarized monopole antennas over the frequency range of $30 \mathrm{kHz}$ to $300 \mathrm{MHz}$, standard cw fields are established at specific field strengths for specified distances from the transmitting monopole on the OATS [58]. The field strength is calculated in terms of the applied voltage, the length and diameter of the transmitting monopole, the distance between the transmitting monopole and the observation point, and its height above the ground plane. The expanded uncertainty of the vertical electric field is estimated to be about $0.1 \mathrm{~dB}$. The receiving antenna is usually far enough away from the transmitting monopole that the field incident on the receiving antenna can be treated as a plane wave (constant amplitude and phase along the receiving antenna). If the separation distance is not large enough, the incident field is not constant along the receiving antenna, and this requires the "non-planarity" correction [59]. There is also another proximity correction that results from the mutual impedance between two monopoles. These non-planarity and proximity corrections can be applied properly to the calculation of the antenna factor. That should eliminate most of the uncertainty associated with these factors. The other sources of uncertainty listed in the standard-antenna method are also applicable for the standard-field method.

\subsection{Standard-Site Method}

The standard-site method requires three sets of attenuation measurements between two different antennas under indentical geometries using three different antennas taken in pairs. Therefore, this method is also called the three-antenna method. If two identical antennas are to be 
calibrated, their antenna factor can be obtained from a single attenuation measurement: thus, this is called the two-antenna method. The standard-site method is based on an ideal (perfect) ground plane, and thus the uncertainty of this calibration method is strongly dependent on the quality of the ground plane. Otherwise, the measurements on which the standard-site method is based are attenuation measurements, i.e., ratio measurements; thus absolute measurements of the power and/or voltage are not necessary. It is, thus, believed to be a relatively accurate measurement provided that the ground plane is ideal. A detailed uncertainty analysis of the standard-site method is currently under study at NIST.

\subsection{Reference-Antenna Method}

The reference-antenna method provides a method of antenna calibration based on the use of a (calibrated) standard antenna. The antenna factor is then derived simply by substitution against the standard antenna. The ratio between the two measurements of received voltage during the substitution is the difference (in decibels) between the antenna factors of the standard antenna and the unknown antenna. The main source of uncertainty in the calibration using this reference antenna method is therefore the uncertainty of antenna factor of the standard antenna used as a reference. The other sources of uncertainty have been discussed previously.

\section{RECEIVER}

Impedance mismatch can exist at both the antenna and the receiver. Antenna impedance mismatch could be accounted for either in the antenna factor calibration or together with receiver impedance mismatch [60]. Some estimates of the combined mismatch contribution to uncertainty have been proposed in references $[1,2,9]$, and they tend to have an expanded uncertainty of approximately $1 \mathrm{~dB}$ depending on the antenna type. Under some assumptions, the probability distribution is U-shaped $[2,60]$, but rectangular or normal would serve as well for setting the expanded uncertainty. Further work is needed here, but it needs to be done in connection with antenna factor calibration and uncertainty analysis.

Receivers for radiated emissions measurements are thoroughly discussed in reference [1, Ch. 3] and uncertainty considerations are covered in reference [1, Ch. 8]. A rectangular probability density with a worst-case uncertainty of $\pm 1.5 \mathrm{~dB}$ is suggested in reference [2], and this is consistent with reference [9]. Bandwidth issues need further study if this value is to be reduced.

\section{CONCLUSIONS AND RECOMMENDATIONS}

In this report we have summarized the major sources of uncertainty in radiated emissions measurements. As indicated in Sections 3 through 7, many uncertainty sources are not well understood and require further study. Consequently, the combined uncertainty and expanded uncertainty $U$ are not well known. This causes a serious difficulty in compliance testing if we follow the approach [2] that the measured emission plus $U$ must be below the emission limit for 
one to state that the EUT complies. We need to know $U$ (or an accurate estimate) to follow this approach. Even if we follow the competing approach [12] that the measurement uncertainty is included in the emission limit, the expected expanded uncertainty is needed to set that limit with confidence. The need for a good estimate of $U$ cannot be avoided.

One difficulty in determining measurement uncertainty for radiated emissions is the large number of uncertainty sources. For example, Table 1 taken from reference [2] lists 13 uncertainty contributions for a measurement of vertically polarized radiated emission performed on an OATS. Most of these items could be the subject of an uncertainty study in their own right, and most of them can be further subdivided into separate uncertainty contributions. For example, the contribution Site imperfections in Table 1 is subdivided into four subtopics in our Section 5.1, and five other types of measurement facilities are discussed in Section 5 . No uncertainty estimates for the contributions Ambient signals and Repeatability of EUT are given in Table 1, and this reflects the difficulty of their evaluation. Actually the contribution Repeatability of EUT is only one of many issues raised in our Section 3 on SETUP OF EQUIPMENT UNDER TEST. Also our subtopics in Section 4 on MEASUREMENT PROCEDURE are not included in Table 1. The overall point is that a complete list of uncertainty components is long and most of them require further study.

A second difficulty in determining measurement uncertainty of radiated emissions is that the separate and combined uncertainties are not necessarily small. Even though the expanded uncertainties in Table 1 [2] are on the order of $4 \mathrm{~dB}$, other estimates that include additional effects give expanded uncertainty estimates on the order of $10 \mathrm{~dB}$ or greater $[1,8]$. When the uncertainties are this large, the standard propagation of uncertainty formulas and RSS combination that are based on first-order Taylor series may not be valid (see Appendix A). Also the use of decibel specification rather than relative values may not be valid when the measured quantity rather than the logarithm is normally distributed.

Even though the importance of determining EMC measurement uncertainty is well recognized [12] and the general methods of quantifying and specifying measurement uncertainty are now agreed upon in the international community [6], further work in radiated emissions measurement uncertainty is clearly needed. Because of the large number of uncertainty components, both experimental and theoretical approaches are needed.

Experimental work can contribute to improved knowledge and statistical data bases in the following areas (in the order of their previous discussion):

- $\quad$ EUT mode of operation

- $\quad$ EUT configuration (including cable layout)

- $\quad$ Measurement procedure (including sampling issues)

- OATS imperfections

- Ambient fields

- Anechoic and semi-anechoic chambers

- Shielded enclosures

- Reverberation chambers

- GTEM cells

- Three-loop system

- Antenna factor 
- Impedance mismatch

- $\quad$ Receivers (including bandwidth issues)

Similarly, theoretical and computational work can contribute to improved knowledge and statistical data bases in the following areas:

- $\quad$ Propagation and combination of uncertainties when uncertainties are not small

- Use of decibel versus relative uncertainty

- $\quad$ EUT configuration (including cable layout)

- Measurement procedure (including sampling issues)

- $\quad$ OATS imperfections

- Anechoic and semi-anechoic chambers

- Reverberation chambers

- Three-loop system

- Antenna factor

- Impedance mismatch

Although this report has addressed only radiated emissions measurement uncertainty, most of the same issues appear for radiated immunity measurements. Maxwell's equations are reciprocal, so many of the same uncertainty quantities can be obtained directly by reciprocity [61]. However, some of the differences in the monitoring of the EUT, the facility use, and the measurement procedure in radiated immunity measurement [1] require separate uncertainty treatment.

\section{REFERENCES}

[1] Bronaugh, E.L.; Lambdin, W.S. Handbook Series on Electromagnetic Interference and Compatibility: Volume 6, Electromagnetic Interference Test Methodology and Procedures. Gainesville, VA: Interference Control Technologies, Inc.; 1988.

[2] The treatment of uncertainty in EMC measurements. NIS 81; National Physical Laboratory, England; 1994.

[3] FCC methods of measurement of radio noise emissions from computing devices. FCC/OST MP-4; July 1987.

[4] Paul, C.R. Introduction to Electromagnetic Compatibility. New York: John Wiley and Sons, Inc.; 1992.

[5] Taylor, B.N.; Kuyatt, C.E. Guidelines for evaluating and expressing the uncertainty of NIST measurement results. Natl. Inst. Stand. Technol. Tech. Note 1297; 1994.

[6] Guide to the expression of uncertainty in measurement. ISO Technical Advisory Group 4 
(TAG 4), Working Group 3 (WG3), 1993.

[7] Wittmann, R.C.; Francis, M.H.; Muth, L.A.; Lewis, R.L. Proposed uncertainty analysis for RCS measurements. Natl. Inst. Stand. Technol. NISTIR 5019; 1994.

[8] White, D.J.R.; Mardiguian, M. Errors in EMC compliance testing and their control. IEEE Int. Symp. Electromag. Compat.: 226-231; 1982.

[9] Taggart, H.E. Radiated EMI instrumentation errors. EMC Technology, 1: 26-35; 1982.

[10] Holland, R.; St. John., R. Statistical response of EM-driven cables inside an overmoded enclosure. IEEE Trans. Electromag. Compat., to be published.

[11] Papoulis, A. Probability, Random Variables, and Stochastic Processes. New York: McGraw-Hill; 1965, Sec. 8-6.

[12] Bronaugh, E.L.; Osburn, J.D.M. A process for the analysis of the physics of measurement and determination of measurement uncertainty in EMC test procedures. IEEE Int. Symp. Electromag. Compat.: 245-249; 1996.

[13] Tai, C.T. Kirchhoff theory: scalar, vector, or dyadic? IEEE Trans. Antennas Propagat., AP-20: 114-115; 1972.

[14] Harrington, R.F. Time-Harnonic Electromagnetic Fields. New York: McGraw-Hill, 1961.

[15] Wang, J.J.H. Generalized Montent Methods in Electromagnetics. New York: John Wiley and Sons; 1991.

[16] Kunz, K.L.; Luebbers, R.J. The Finite Difference Time Domain Method for Electromagnetics. Boca Raton: CRC Press; 1993.

[17] Weston, D.A. Electromagnetic Compatibility. New York: Marcel Dekker, Inc.; 1991.

[18] Sattler, F.; Gonschorek, K.-H. Measurement and computation of cable coupling in arbitrary environment. IEEE Int. Symp. Electromag. Compat.: 5-10; 1994.

[19] Bucci, O.M.; D'Elia, G. Advanced sampling techniques in electromagnetics. Ch. 8 in Review of Radio Science, 1993-1996, W.R. Stone, editor. Oxford University Press; 1996.

[20] James, G.L. Geometrical Theory of Diffraction for Electromagnetic Waves. London: Peter Perigrinus Ltd.; 3rd edition, 1986. 
[21] Heise, E.R.; Heise, R.E. A method to compute open area test site uncertainty using ANSI C63.4 normalized site attenuation measurement data. IEEE Int. Symp. Electromag. Compat.: 505-507; 1996.

[22] Kerr, D.E. Propagation of Short Radio Waves. New York: McGraw-Hill Book Co.; 1951, Sec. 5.4.

[23] Ishimaru, A. Wave Propagation and Scattering in Random Media. New York: Academic Press; 1978, Sec. 21-2.

[24] Hill, D.A.; Wait, J.R. Electromagnetic scattering from an unbonded rectangular wire mesh located near the air-ground interface. IEEE Trans. Electromag. Compat., Vol. 19: 170-174; 1977.

[25] Jordan, E.C.; Balmain, K.G. Electromagnetic Waves and Radiating Systems. Englewood Cliffs, NJ: Prentice-Hall; 1968, Section 16.01.

[26] Halaberda, W.B.; Rivers, J.H. Measurement comparisons of radiated test facilities. IEEE Int. Symp. Electromag. Compat.: 401-406; 1992.

[27] Kolb, L.E. Statistical comparison of site-to-site measurement reproducibility. IEEE Int. Symp. Electromag. Compat.: 241-244; 1996.

[28] ANSI C63.4-1991, American national standard for methods of measurement of radionoise emissions from low-voltage electrical and electronic equipment in the range of $9 \mathrm{kHz}$ to $40 \mathrm{GHz}$.

[29] Yang, C.-F.; Burnside, W.D.; Rudduck, R.C. A doubly periodic moment method solution for analysis and design of an absorber covered wall. IEEE Trans. Antennas Propagat., 41: 600-609,1993.

[30] Tofani, S.; Ondrejka, A.R.; Kanda, M. Time-domain method for characterizing the reflectivity of absorbing materials from 30 to $1000 \mathrm{MHz}$. IEEE Trans. Electromag. Compat., 33: 234-240; 1991.

[31] Tofani, S.; Ondrejka, A.R.; Kanda, M.; Hill, D.A. Bistatic scattering of absorbing materials from 30 to $1000 \mathrm{MHz}$. IEEE Trans. Electromag. Compat., 34: 304-307; 1992.

[32] McConnell, R.A.; Vitek, C. Calibration of fully anechoic rooms and correlation with OATS Measurements. IEEE Int. Symp. Electromag. Compat.: 134-139; 1996.

[33] Cruz, J.E.; Larsen, E.B. Assessment of error bounds for some typical MIL-STD-461/462 types of measurements. Nat. Bur. Stand. (U.S.) Technical Note 1300; 1986. 
[34] Camell, D.; Koepke, G.; Smith, R.; Rakoski, B. A standard source method for reducing antenna factor errors in shielded room measurements. Natl. Inst. Stand. Technol. Tech. Note $1382 ; 1996$.

[35] Koepke, G.; Randa, J. Screened-room measurements on the NIST spherical-dipole standard radiator. J. Res. Natl. Inst. Stand. Technol., 99: 737-749; 1994.

[36] Military Standard, Measurement of Electromagnetic Interference Characteristics, MILSTD-462D, 11 January 1993.

[37] Crawford, M.L.; Koepke, G.H. Design, evaluation, and use of a reverberation chamber for performing electromagnetic susceptibility/vulnerability measurements. Nat. Bur. Stand. (U.S.) Technical Note 1092; 1986.

[38] Hill, D.A. Electronic mode stirring for reverberation chambers. IEEE Trans. Electromag. Compat., 36: 294-299; 1994.

[39] Crawford, M.L.; Loughry, T.A.; Hatfield, M.O.; Freyer, G.J. Band-limited, white Gaussian noise excitation for reverberation chambers and applications to radiated susceptibility testing. Natl. Inst. Stand. Technol. Tech. Note 1375; 1996.

[40] Reverberating chamber for total radiated power measurement. CISPR/IEC EMC Std 16I; 1993.

[41] Hill, D.A.; Camell, D.G.; Cavcey, K.H.; Koepke, G.H. Radiated emissions and immunity of microstrip transmission lines: theory and reverberation chamber measurements. IEEE Trans. Electromag. Compat., 38: 165-172; 1996.

[42] Ladbury, J.M.; Koepke, G.H.; Camell, D.G. Evaluation of the NASA Langley Research Center mode-stirred chamber facility. Natl. Inst. Stand. Technol. Tech. Note; in preparation.

[43] Sreenivasiah, I.; Chang, D.C.; Ma, M.T. Emission characteristics of electrically small radiating sources from tests inside a TEM cell. IEEE Trans. Electromag. Compat., 23: $113-121 ; 1981$.

[44] Hill, D. Bandwidth limitations of TEM cells due to resonances. J. Microwave Power, 18: 181-195; 1983.

[45] Kanda, M.; Orr, R.D. Generation of standard electromagnetic fields in a TEM cell. Nat. Bur. Stand. (U.S.) Technical Note 1319; 1988.

[46] Wilson, P. On correlating TEM cell and OATS emission measurements. IEEE Trans. 
Electromag. Compat., 37: 1-16; 1995.

[47] Kanda, M.; Hill, D.A. A three-loop system for determining the radiation characteristics of an electrically small source. IEEE Trans. Electromag. Compat., 34: 1-3; 1992.

[48] Novotny, D.R.; Masterson, K.D.; Kanda, M. An optically linked three-loop antenna system for determining the radiation characteristics of an electrically small source. IEEE Int. Symp. Electromag. Compat.: 300-305; 1993.

[49] American National Standard for Calibration of Antennas Used For Radiated Emission Measurements in Electromagnetic Interference (EMI) Control, ANSI C63.5, 1988.

[50] Kanda, M. Standard antennas for electromagnetic interference measurements and methods to calibrate them. IEEE Trans. Electromag. Compat., 36: 261-273; 1994.

[51] Kanda, M. Standard probes for electromagnetic field measurements. IEEE Trans. Antennas Propagat., 41: 1349-1364; 1993.

[52] Camell, D.G.; Larsen, E.B.; Cruz, J.E. NBS calibration procedures for horizontal dipole antennas (25 to $1000 \mathrm{MHz}$ ). Nat. Bur. Stand. (U.S.) Technical Note 1309; 1987.

[53] Schelkunoff, S.A.; Friis, H.T. Antennas, Theory and Practice. New York: Wiley; 1952.

[54] Kanda, M.; Orr, R.D. Near-field gain of a horn and an open-ended waveguide: comparison theory and experiment. IEEE Trans. Antennas Propagat., 35: 33-44; 1987.

[55] Wu, D.I.; Kanda, M. Comparison of theoretical and experimental data for the near field of an open-ended rectangular waveguide. IEEE Trans. Electromag. Compat., 31: 353-358; 1989.

[56] Jull, E.V. Finite-range gain of sectoral and pyramidal horns. Electron. Lett., 6: 680-681; 1970.

[57] Hill, D.A.; Kanda, M.; Larsen, E.B.; Koepke, G.H.; Orr, R.D. Generating standard reference fields in the NIST anechoic chamber. Natl. Inst. Stand. Technol. Tech. Note $1335 ; 1990$.

[58] Camell, D.G.; Larsen, E.B.; Cruz, J.E.; Hill, D.A. NIST calibration procedure for vertically polarized monopole antennas. Natl. Inst. Stand. Technol. Tech. Note 1347; 1991.

[59] Randa, J.P. Correction factor for nonplanar incident field in monopole calibrations. IEEE Trans. Electromag. Compat., 35: 94-96; 1993. 
[60] Harris, I.A.; Warner, F.L. Re-examination of mismatch uncertainty when measuring microwave power and attenuation. IEE Proc., 128, Pt. H: 35-45; 1981.

[61] Monteath, G.D. Applications of the Electromagnetic Reciprocity Principle. Oxford: Pergamon Press; 1973.

[62] Ku, H.H. Notes on the use of propagation of error formulas. J. Res. Nat. Bur. Std. (U.S.) 70C: $263-273 ; 1966$.

\section{APPENDIX A. PROPAGATION OF UNCERTAINTY}

In many cases a radiated emission $Y$ is not measured directly, but is determined from a functional relationship $f$ of $N$ other quantities $X_{1}, X_{2}, \ldots, X_{N}$ :

$$
Y=f\left(X_{1}, X_{2}, \ldots, X_{N}\right)
$$

Here the function $f$ should represent the entire measurement process and should include all quantities that contribute to the measurement uncertainty. The measurement estimate $y$ is obtained from eq (A-1) using estimates $x_{1}, x_{2}, \ldots, x_{N}$ :

$$
y=f\left(x_{1}, x_{2}, \ldots, x_{N}\right) .
$$

If we expand eq (A-2) in a first-order Taylor series, we can evaluate the mean of $(y-Y)^{2}$ to obtain the combined standard uncertainty $u_{c}(y)$ in the following form [5]:

$$
u_{c}^{2}(y)=\sum_{i=1}^{N}\left(\frac{\partial f}{\partial x_{i}}\right)^{2} u^{2}\left(x_{i}\right)+2 \sum_{i=1}^{N-1} \sum_{j i=1}^{N} \frac{\partial f}{\partial x_{i}} \frac{\partial f}{\partial x_{j}} u\left(x_{i}, x_{j}\right),
$$

where the partial derivatives $\partial f / \partial x_{i}$ (often referred to as sensitivity coefficients) are equal to $\partial f / \partial X_{i}$ evaluated at $X_{i}=x_{i}, u\left(x_{i}\right)$ is the standard uncertainty associated with the input estimate $x_{i}$, and $u\left(x_{i}, x_{j}\right)$ is the estimated covariance associated with $x_{i}$ and $x_{j}$

Because eq (A-3) is derived from the first-order Taylor series expansion of $f$, it contains only first-order derivatives of $f$ with respect to $x_{i}$. Even so, it does not fit the RSS form in eq (1) because of the covariance terms in the double summation. The result of the double sum in eq (A-3) can be either positive or negative because the partial derivatives and the covariances can be positive or negative. In the very worst case where the uncertainties are perfectly correlated, 
$u\left(x_{i}, x_{j}\right)=u\left(x_{i}\right) u\left(x_{j}\right)$, the right side of eq (A-3) is a perfect square. Then the square root of eq (A-3) yields

$$
u_{c}(y)=\sum_{i=1}^{N}\left|\frac{\partial f}{\partial x_{i}}\right| u\left(x_{i}\right)=\sum_{i=1}^{N} u_{i},
$$

where we have assumed that all $\partial f l \partial x_{i}$ factors are positive (or negative) to yield the worst case. The linear sum in eq (4) clearly gives a larger combined uncertainty than the RSS sum in eq (1), and this is the recommended form in reference [2] for cases of "adverse correlation."

If the covariances are zero $\left(x_{i}\right.$ and $x_{j}$ are uncorrelated for $\left.i \neq j\right)$, then eq (A-3) reduces to

$$
u_{c}^{2}(y)=\sum_{i=1}^{N}\left(\frac{\partial f}{\partial x_{i}}\right)^{2} u^{2}\left(x_{i}\right)=\sum_{i=1}^{N} u_{i}^{2},
$$

where we have defined $u_{i}=\left(\partial f / \partial x_{i}\right) u\left(x_{i}\right)$. Equation (A-5) now fits the RSS form in eq (1). However, it is important to recognize that the derivation of eq (A-5) requires that terms higher than first order in the Taylor series expansion for $y$ are negligible and that $x_{i}$ and $x_{j}$ are uncorrelated.

To examine the requirement that higher-order terms must be negligible for the validity of eq (A-5), we start by writing a Taylor series of eq (A-2) including terms up to second order:

$$
\begin{aligned}
y-Y & =\sum_{i=1}^{N} \frac{\partial f}{\partial x_{i}}\left(x_{i}-X_{i}\right)+\frac{1}{2} \sum_{i=1}^{N} \frac{\partial^{2} f}{\partial x_{i}^{2}}\left(x_{i}-X_{i}\right)^{2} \\
& +\sum_{i=1}^{N-1} \sum_{j=i+1}^{N} \frac{\partial^{2} f}{\partial x_{i} \partial x_{j}}\left(x_{i}-X_{i}\right)\left(x_{j}-X_{j}\right)+\text { higher order terms . }
\end{aligned}
$$

Following the mathematics for the evaluation [62] of the mean of $(y-Y)^{2}$, we find that the first correction to the right side of eq (A-5) is a summation of cubic terms of the following form

$$
\sum_{i=1}^{N} \frac{\partial f}{\partial x_{i}} \frac{\partial^{2} f}{\partial x_{i}^{2}} \gamma_{i} u^{3}\left(x_{i}\right)
$$

where $\gamma_{\mathrm{i}}$ is a measure of skewness given by $\gamma_{i}=$ [mean $\left.\left(x_{i}-X_{i}\right)^{3}\right] / u^{3}\left(x_{i}\right)$. If all of the $x_{i}$ 's have a symmetrical distribution, then all of the $\gamma_{i}^{\prime}$ 's are zero and the summation of cubic terms in eq (A-7) 
vanishes.

The next higher-order corrections to the right side of eq $(A-5)$ involve summations of fourth power terms of the following form [62]:

$$
\frac{1}{4} \sum_{i=1}^{N}\left(\frac{\partial^{2} f}{\partial x_{i}^{2}}\right)^{2}\left(\Gamma_{i}-1\right) u^{4}\left(x_{i}\right)+\sum_{i=1}^{N-1} \sum_{j=i+1}^{N}\left(\frac{\partial^{2} f}{\partial x_{i} \partial x_{j}}\right)^{2} u^{2}\left(x_{i}\right) u^{2}\left(x_{j}\right)
$$

where $\Gamma_{i}$ is related to the elongation [62] and is given by $\Gamma_{i}=\left[\operatorname{mean}\left(x_{i}-X_{i}\right)^{4}\right] / u^{4}\left(x_{i}\right)$. For a normal distribution, $\Gamma_{i}=3$. In this case the higher-order correction terms in eq (A-8) reduce to

$$
\frac{1}{2} \sum_{i=1}^{N}\left(\frac{\partial^{2} f}{\partial x_{i}^{2}}\right)^{2} u^{4}\left(x_{i}\right)+\sum_{i=1}^{N-1} \sum_{j=i+1}^{N}\left(\frac{\partial^{2} f}{\partial x_{i} \partial x_{j}}\right)^{2} u^{2}\left(x_{i}\right) u^{2}\left(x_{j}\right)
$$

If $f$ is a linear function of the $X_{i}$, then the second-order derivatives are zero, and the correction terms in eq (A-9) are zero regardless of the values of $u\left(x_{i}\right)$. For general functions $f$, the correction terms in eq (A-9) are not zero and are small only if $u\left(x_{i}\right)$ or the partial derivatives are small.

\section{APPENDIX B. UNCERTAINTY OF A PRODUCT OF QUANTITIES}

In general the propagation of uncertainty requires the evaluation of partial derivatives with respect to estimated quantities, and the expressions in Appendix A cannot be simplified further without specifying the function $f$. The special case where $f$ is a product is interesting because all the partial derivatives are easily evaluated and the results are conveniently cast in terms of relative uncertainties of the individual estimates [2]. A simple example is the case where a radiated electric field is the product of the antenna factor and the received voltage.

For a product of $\mathrm{N}$ quantities, $\mathrm{Y}$ is given by

$$
Y=X_{1} X_{2} \ldots X_{N}
$$

The measurement estimate $\mathrm{y}$ is similarly given by a product of the estimates $x_{l}, x_{2}, \ldots, x_{N}$ :

$$
y=x_{1} x_{2} \ldots x_{N} .
$$

The individual standard uncertainties $u_{i}$ can be written 


$$
u_{i}=\left|\frac{\partial f}{\partial x_{i}}\right| u\left(x_{i}\right)=\left|\frac{f}{x_{i}}\right| u\left(x_{i}\right)=|f| \frac{u\left(x_{i}\right)}{\left|x_{i}\right|} .
$$

Hence $u_{i}$ is proportional to the relative standard uncertainty $u\left(x_{i}\right) /\left|x_{i}\right|$.

For the case of perfectly correlated uncertainties, we can substitute eq (B-3) into eq (A-4) to obtain the combined relative uncertainty:

$$
\frac{u_{c}(y)}{|y|}=\sum_{i} \frac{u\left(x_{i}\right)}{\left|x_{i}\right|} .
$$

Here the relative combined relative is seen to be the linear sum of the individual relative uncertainties. For the case of uncorrelated uncertainties, we can substitute eq (B-3) into eq (A-5) to obtain

$$
\left(\frac{u_{c}(y)}{|y|}\right)^{2}=\sum_{i}\left(\frac{u\left(x_{i}\right)}{\left|x_{i}\right|}\right)^{2} .
$$

In this case the relative combined uncertainty fits the RSS form. If we attempt to write eq (A-5) in terms of relative uncertainties for a general function $f$, then the result is

$$
\left(\frac{u_{c}(y)}{|y|}\right)^{2}=\sum_{i}\left(\frac{\partial f}{\partial x_{i}} \frac{x_{i}}{y}\right)^{2}\left(\frac{u\left(x_{i}\right)}{\left|x_{i}\right|}\right)^{2} .
$$

When $f$ has the product form as in eq (B-2), then the first factor in the summation is equal to 1 and eq (B-6) reduces to (B-5).

Following Appendix A, we can evaluate the higher correction terms to eq (B-5) for the special case of the product function. The cubic correction term in eq (A-7) is zero because the second derivative of $f$ with respect to $x_{i}$ is zero. The first summation in eq (A-8) is also zero because the same second partical derivative is zero. The second partial derivative in the double summation reduces to

$$
\frac{\partial^{2} f}{\partial x_{i} \partial x_{j}}=\frac{y}{x_{i} x_{j}}
$$

Thus the first nonzero correction to eq (B-5) is 


$$
\sum_{i=1}^{N-1} \sum_{j=i+1}^{N}\left(\frac{u\left(x_{i}\right)}{x_{i}}\right)^{2}\left(\frac{u\left(x_{j}\right)}{x_{j}}\right)^{2}
$$

which involves a product of the squares of relative uncertainties.

Many EMC measurements are expressed in decibels relative to some convenient reference level. If $Y$ in eq (B-1) represents power, then we can rewrite eq (B-1) as

$$
y(\mathrm{~dB})=10 \log _{10}\left(x_{1} x_{2} \ldots x_{N}\right)=\sum_{i=1}^{N} x_{i}(\mathrm{~dB}) \text {. }
$$

If we make the convenient assumption of a log normal distribution for $y$ and $x_{i}$, then $y(\mathrm{~dB})$ and $x_{i}$ $(\mathrm{dB})$ are normally distributed, and we can write the combined uncertainty in the RSS form:

$$
u_{c}(y)(\mathrm{dB})=\sqrt{\sum_{i=1}^{N} u^{2}\left(x_{i}\right)(\mathrm{dB}) .}
$$

Since all of the higher-order partial derivatives are zero, all of the higher-order correction terms for eq (B-10) are zero, and eq (B-10) is exact. (This assumes the original convenient log-normal assumption.) 
Table 1. Measurement uncertainty of vertically polarized electric field strength over the frequency range $30 \mathrm{MHz}$ to $1 \mathrm{GHz}$ on an open area test site at $3 \mathrm{~m}$ and $10 \mathrm{~m}$ [2].

\begin{tabular}{|c|c|c|c|c|c|}
\hline \multirow{3}{*}{ Contribution } & \multirow{3}{*}{$\begin{array}{l}\text { Probability } \\
\text { Distribution }\end{array}$} & \multicolumn{4}{|c|}{ Uncertainty $(\mathrm{dB})$} \\
\hline & & \multicolumn{2}{|c|}{ Biconical Antenna } & \multicolumn{2}{|c|}{$\begin{array}{c}\text { Log periodic } \\
\text { Antenna }\end{array}$} \\
\hline & & $3 \mathrm{~m}$ & $10 \mathrm{~m}$ & $3 \mathrm{~m}$ & $10 \mathrm{~m}$ \\
\hline Ambient signals & & - & - & - & - \\
\hline Antenna factor calibration & normal $(\mathrm{k}=2)$ & \pm 1.8 & \pm 1.0 & \pm 1.0 & \pm 1.0 \\
\hline Cable loss calibration & normal $(\mathrm{k}=2)$ & \pm 1.5 & \pm 0.5 & \pm 0.6 & \pm 0.5 \\
\hline Receiver specification & rectangular & \pm 1.5 & \pm 1.5 & \pm 1.5 & \pm 1.5 \\
\hline Antenna directivity & rectangular & $\begin{array}{c}+0.5 \\
0\end{array}$ & 0 & $\begin{array}{c}+3.0 \\
0\end{array}$ & $\begin{array}{c}+0.5 \\
0\end{array}$ \\
\hline Antenna factor variation with height & rectangular & \pm 2.0 & \pm 2.0 & \pm 0.5 & \pm 0.5 \\
\hline Antenna phase center variation & rectangular & $:$ & 0 & \pm 1.0 & \pm 0.2 \\
\hline Antenna factor frequency interpolation & rectangular & \pm 0.25 & \pm 0.25 & \pm 0.25 & \pm 0.25 \\
\hline Measurement distance variation & rectangular & \pm 0.6 & \pm 0.4 & \pm 0.6 & \pm 0.4 \\
\hline Site imperfections & rectangular & \pm 2.0 & \pm 2.0 & \pm 2.0 & \pm 2.0 \\
\hline $\begin{array}{l}\text { Mismatch } \\
\text { Receiver VRC: } \Gamma_{1}=0.2 \\
\text { Antenna VRC: } \Gamma_{\mathrm{g}}=0.67(\mathrm{Bi}) 0.3(\mathrm{Lp}) \\
\text { Uncertainty limits } 20 \mathrm{Log}\left(1 \pm \Gamma_{1} \Gamma_{\mathrm{g}}\right)\end{array}$ & U-shaped & $\begin{array}{l} \pm 1.1 \\
-1.25\end{array}$ & $\begin{array}{l} \pm 1.1 \\
-1.25\end{array}$ & \pm 0.5 & \pm 0.5 \\
\hline $\begin{array}{l}\text { System repeatability (previous assessment } \\
\text { of } s\left(q_{k}\right) \text { from } 5 \text { repeats, } 1 \text { reading on EUT) }\end{array}$ & std. deviation & \pm 0.5 & \pm 0.5 & \pm 0.5 & \pm 0.5 \\
\hline Repeatability of EUT & & - & - & - & - \\
\hline Combined standard uncertainty $\mathrm{u}_{\mathrm{c}}(\mathrm{y})$ & normal & $\begin{array}{l}+2.19 \\
-2.21\end{array}$ & $\begin{array}{l}+2.16 \\
-2.20\end{array}$ & $\begin{array}{l}+2.52 \\
-1.82\end{array}$ & $\begin{array}{l}+1.74 \\
-1.72\end{array}$ \\
\hline Expanded uncertainty $U$ & normal $(\mathrm{k}=2)$ & $\begin{array}{l}+4.38 \\
-4.42\end{array}$ & $\begin{array}{l}+4.32 \\
-4.40\end{array}$ & $\begin{array}{l}+5.04 \\
-3.64\end{array}$ & $\begin{array}{l}+3.48 \\
-3.44\end{array}$ \\
\hline
\end{tabular}




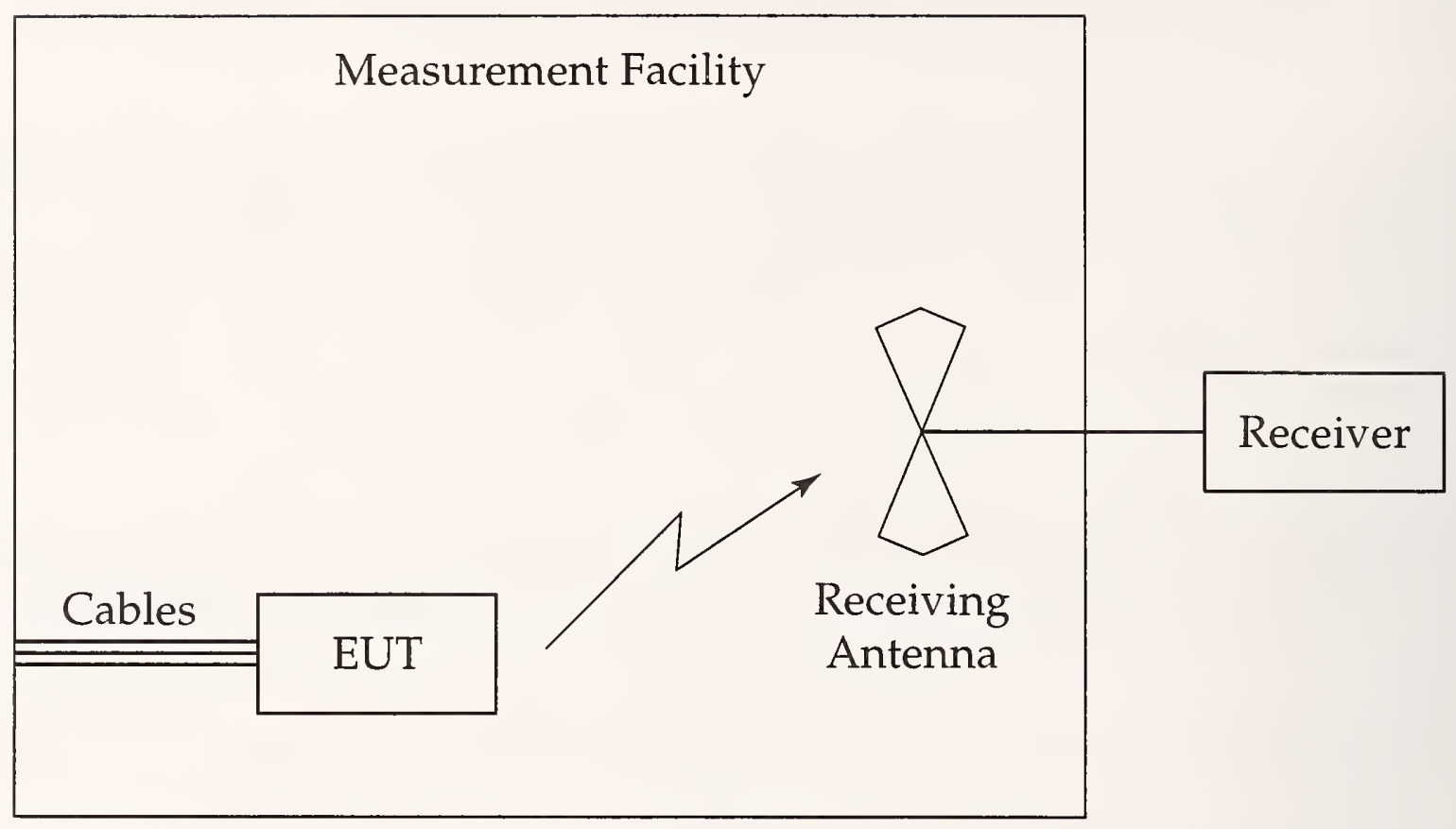

Figure 1. Generic setup for a radiated emissions measurement.

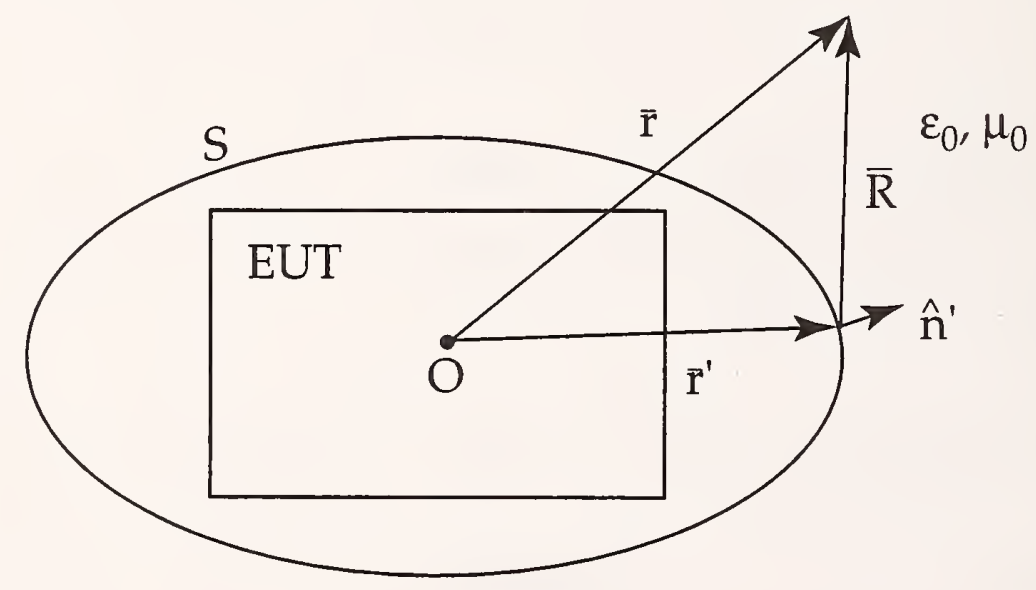

Figure 2. Geometry for radiation from a surface surrounding an EUT. 


$$
\varepsilon_{0}, \mu_{0}
$$

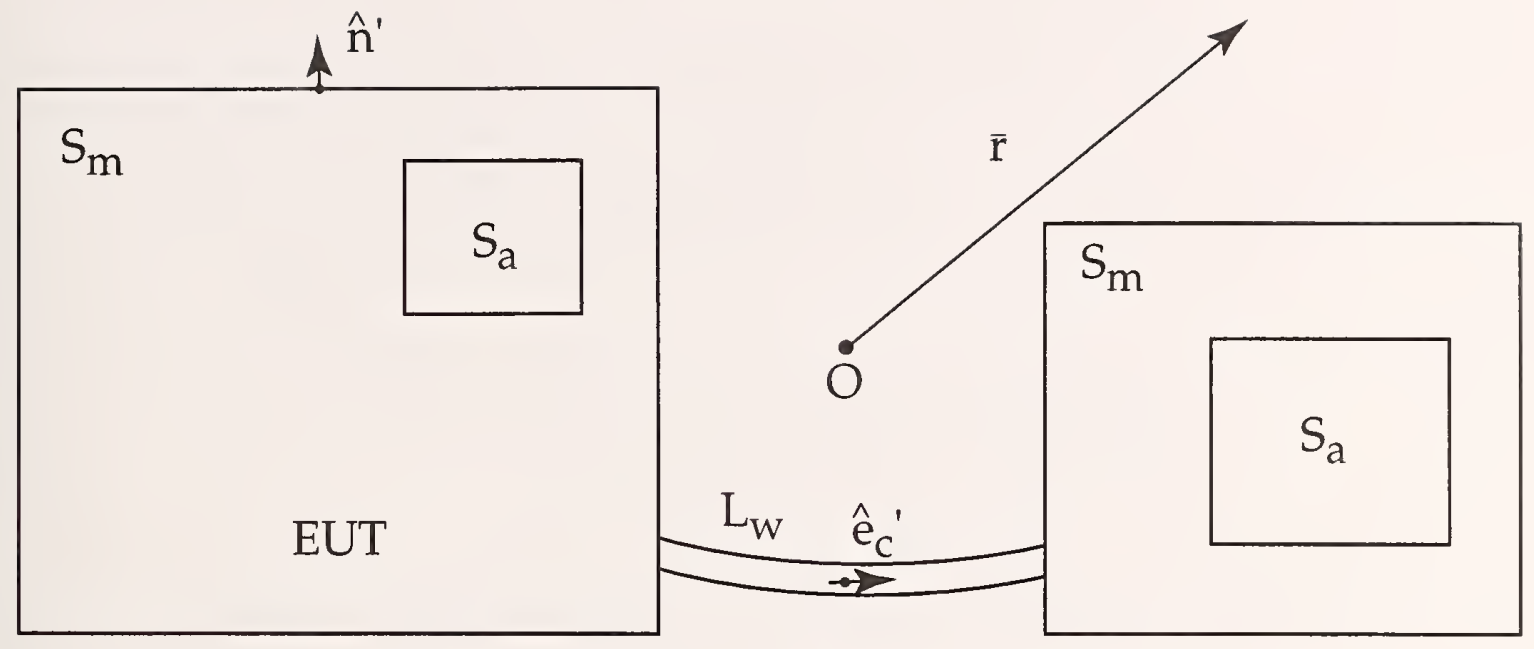

Figure 3. Geometry for radiation from surface currents, cable currents, and apertures.

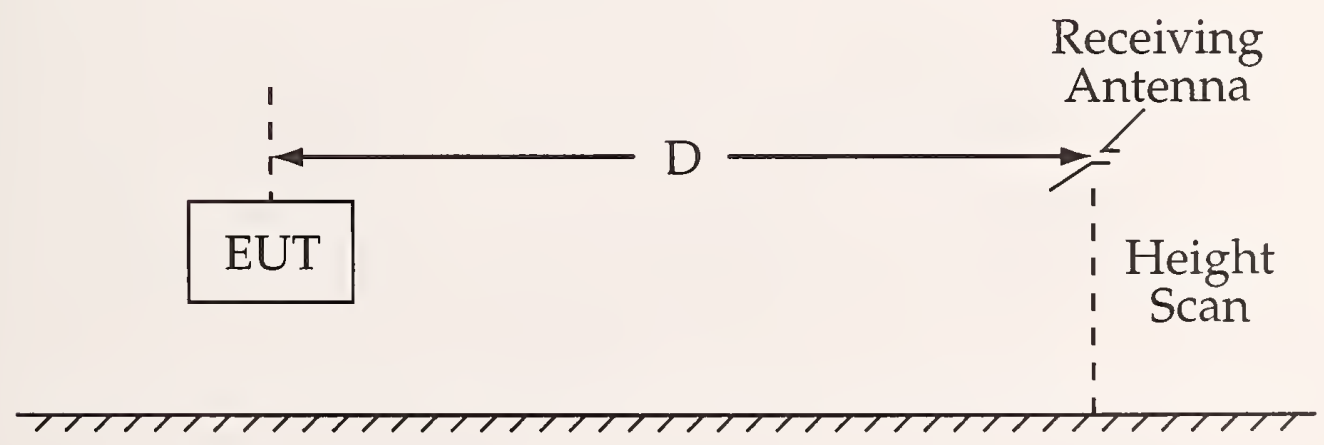

Figure 4. Setup for radiated emissions measurement on an OATS. 


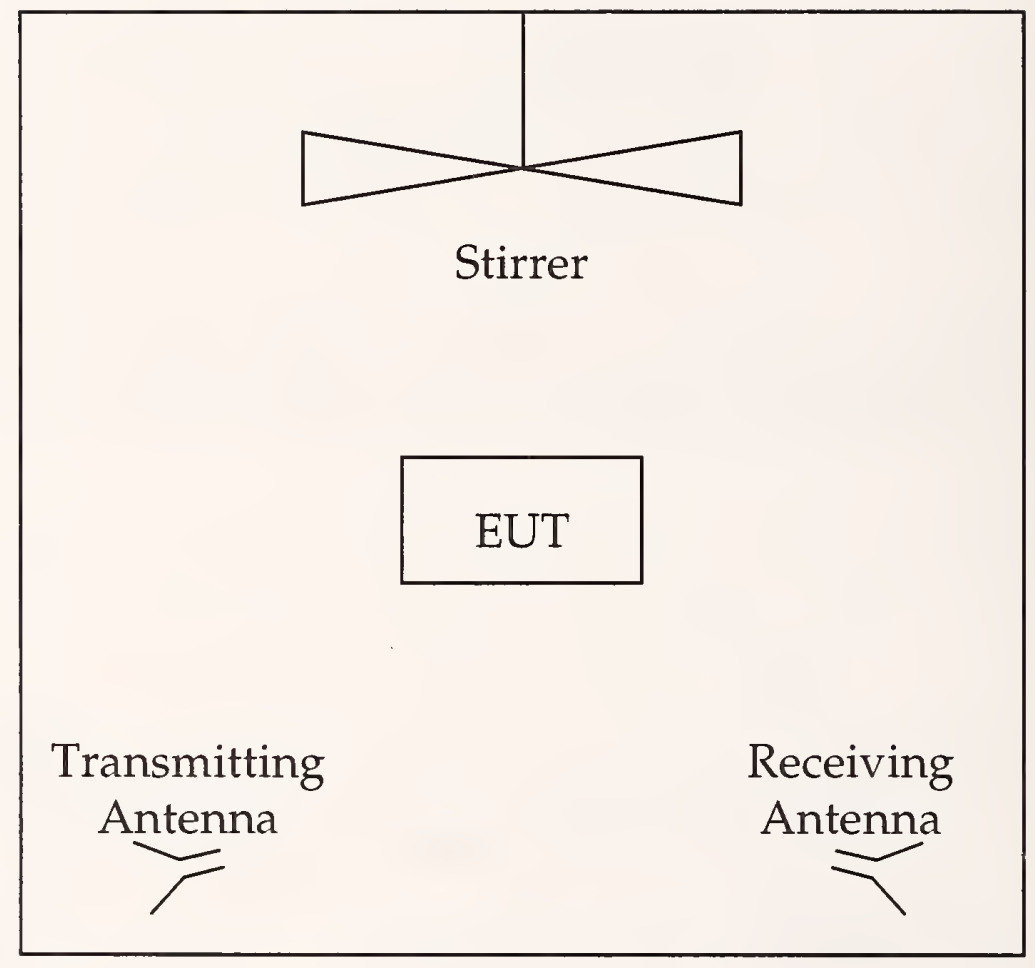

Figure 5. Setup for radiated emissions measurement in a reverberation chamber. 


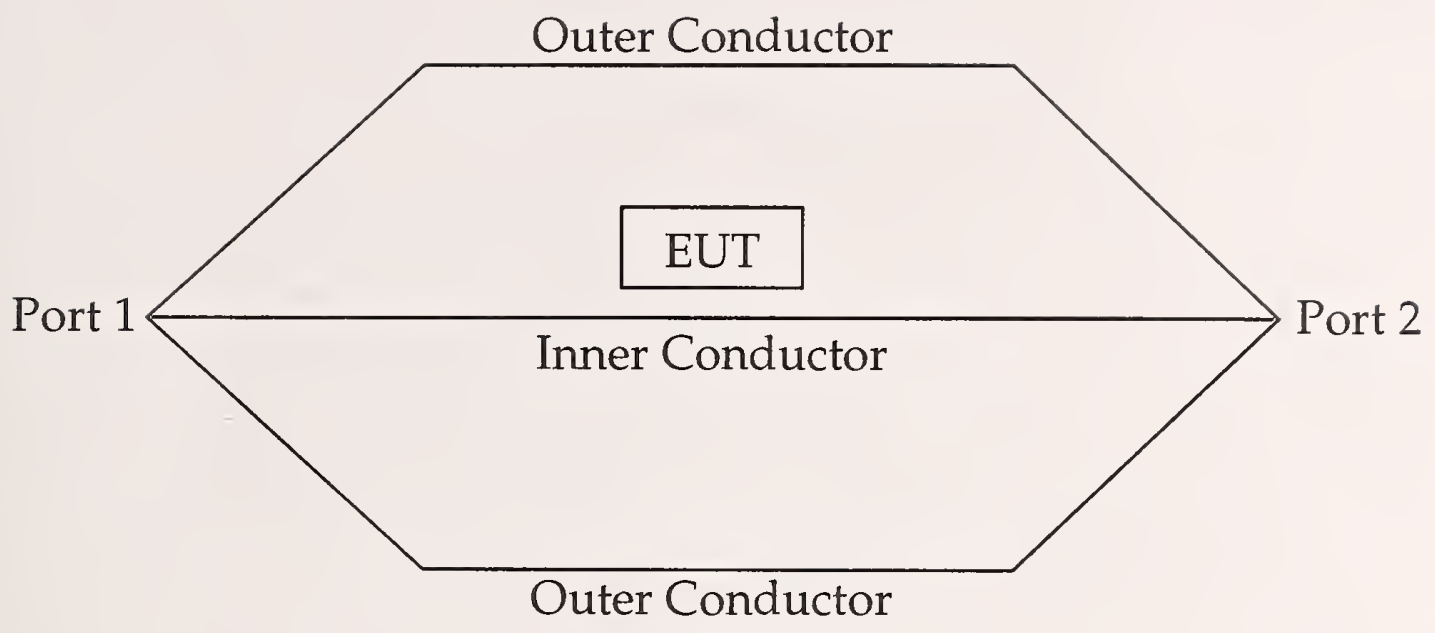

Figure 6. Setup for radiated emissions measurement in a TEM cell.

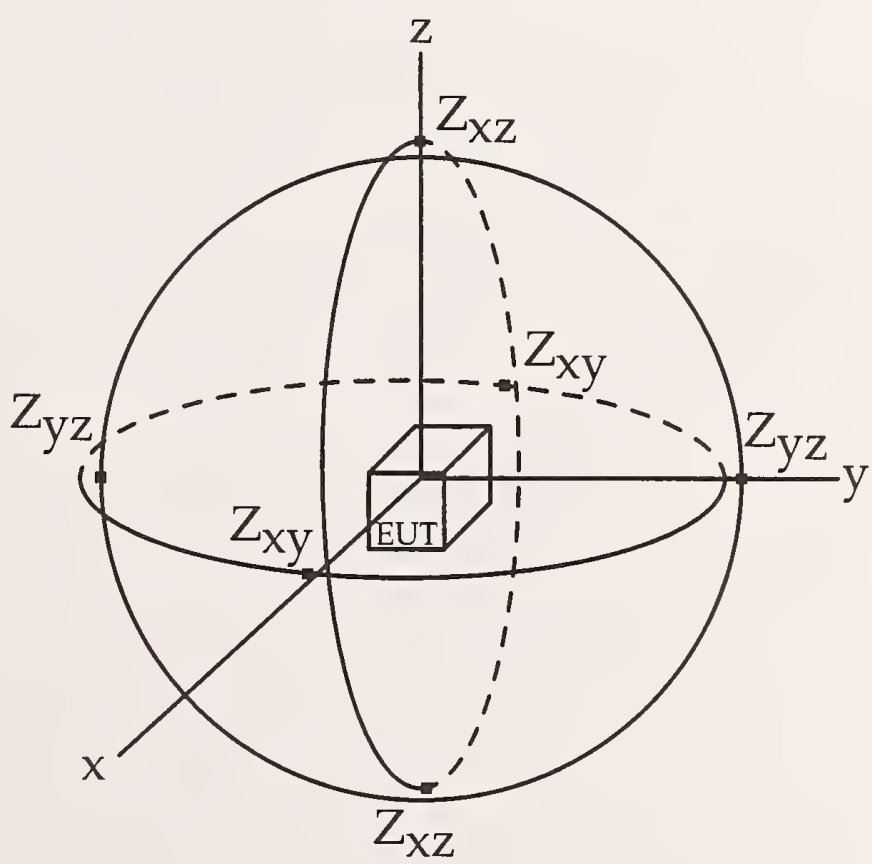

Figure 7. Setup for radiated emissions measurement with a three-loop antenna system. 


\section{Periodical}

Journal of Research of the National Institute of Standards and Technology-Reports NIST research and development in those disciplines of the physical and engineering sciences in which the Institute is active. These include physics, chemistry, engineering, mathematics, and computer sciences. Papers cover a broad range of subjects, with major emphasis on measurement methodology and the basic technology underlying standardization. Also included from time to time are survey articles on topics closely related to the Institute's technical and scientific programs. Issued six times a year.

\section{Nonperiodicals}

Monographs-Major contributions to the technical literature on various subjects related to the Institute's scientific and technical activities.

Handbooks-Recommended codes of engineering and industrial practice (including safety codes) developed in cooperation with interested industries, professional organizations, and regulatory bodies.

Special Publications-Include proceedings of conferences sponsored by NIST, NIST annual reports, and other special publications appropriate to this grouping such as wall charts, pocket cards, and bibliographies.

Applied Mathematics Series-Mathematical tables, manuals, and studies of special interest to physicists, engineers, chemists, biologists, mathematicians, computer programmers, and others engaged in scientific and technical work.

National Standard Reference Data Series-Provides quantitative data on the physical and chemical properties of materials, compiled from the world's literature and critically evaluated. Developed under a worldwide program coordinated by NIST under the authority of the National Standard Data Act (Public Law 90-396). NOTE: The Journal of Physical and Chemical Reference Data (JPCRD) is published bimonthly for NIST by the American Chemical Society (ACS) and the American Institute of Physics (AIP). Subscriptions, reprints, and supplements are available from ACS, 1155 Sixteenth St., NW, Washington, DC 20056.

Building Science Series-Disseminates technical information developed at the Institute on building materials, components, systems, and whole structures. The series presents research results, test methods, and performance criteria related to the structural and environmental functions and the durability and safety characteristics of building elements and systems.

Technical Notes-Studies or reports which are complete in themselves but restrictive in their treatment of a subject. Analogous to monographs but not so comprehensive in scope or definitive in treatment of the subject area. Often serve as a vehicle for final reports of work performed at NIST under the sponsorship of other government agencies.

Voluntary Product Standards-Developed under procedures published by the Department of Commerce in Part 10, Title 15, of the Code of Federal Regulations. The standards establish nationally recognized requirements for products, and provide all concerned interests with a basis for common understanding of the characteristics of the products. NIST administers this program in support of the efforts of privatesector standardizing organizations.

Consumer Information Series-Practical information, based on NIST research and experience, covering areas of interest to the consumer. Easily understandable language and illustrations provide useful background knowledge for shopping in today's technological marketplace.

Order the above NIST publications froin: Superintendent of Documents, Government Printing Office, Washington, DC 20402.

Order the following NIST publications-FIPS and NISTIRs-from the National Technical Information Service, Springfield, VA 22161.

Federal Information Processing Standards Publications (FIPS PUB)-Publications in this series collectively constitute the Federal Information Processing Standards Register. The Register serves as the official source of information in the Federal Government regarding standards issued by NIST pursuant to the Federal Property and Administrative Services Act of 1949 as amended, Public Law 89-306 (79 Stat. 1127), and as implemented by Executive Order 11717 (38 FR 12315, dated May 11, 1973) and Part 6 of Title 15 CFR (Code of Federal Regulations).

NIST Interagency Reports (NISTIR)-A special series of interim or final reports on work performed hy NIST for outside sponsors (both government and non-government). In general, initial distribution is handled by the sponsor; public distribution is by the National Technical lnformation Service, Springtield. VA 22161, in paper copy or microfiche form. 
U.S. Department of Commerce

National Institute of Standards and Technology 325 Broadway

Boulder, Colorado 80303-3328

Official Business

Penalty for Private Use, $\$ 300$ 